\title{
Metabotropic Glutamate Receptor 7 Modulates the Rewarding Effects of Cocaine in Rats: Involvement of a Ventral Pallidal GABAergic Mechanism
}

\author{
Xia Li', Jie Li', Xiao-Qing Peng', Krista Spiller', Eliot L Gardner' and Zheng-Xiong Xi*,' \\ 'Neuropsychopharmacology Section, Chemical Biology Research Branch, Intramural Research Program, National Institute on Drug Abuse, \\ Baltimore, MD, USA
}

\begin{abstract}
The metabotropic glutamate receptor 7 (mGluR7) has received much attention as a potential target for the treatment of epilepsy, major depression, and anxiety. In this study, we investigated the possible involvement of mGluR7 in cocaine reward in animal models of drug addiction. Pretreatment with the selective mGluR7 allosteric agonist N,N'-dibenzyhydryl-ethane-I,2-diamine dihydrochloride (AMN082; $1-20 \mathrm{mg} / \mathrm{kg}$, i.p.) dose-dependently inhibited cocaine-induced enhancement of electrical brain-stimulation reward and intravenous cocaine self-administration under both fixed-ratio and progressive-ratio reinforcement conditions, but failed to alter either basal or cocaine-enhanced locomotion or oral sucrose self-administration, suggesting a specific inhibition of cocaine reward. Microinjections of AMN082 ( $1-5 \mu \mathrm{g} / \mu \mathrm{l}$ per side) into the nucleus accumbens (NAc) or ventral pallidum (VP), but not dorsal striatum, also inhibited cocaine self-administration in a dose-dependent manner. Intra-NAc or intra-VP co-administration of 6-(4-methoxyphenyl)-5-methyl-3-pyridin4-ylisoxazolo[4,5-c]pyridin-4(5H)-one (MMPIP, $5 \mu \mathrm{g} / \mu \mathrm{l}$ per side), a selective mGluR7 allosteric antagonist, significantly blocked AMN082's action, suggesting an effect mediated by $\mathrm{mGluR7}$ in these brain regions. In vivo microdialysis demonstrated that cocaine (I0 mg/kg, i.p.) priming significantly elevated extracellular DA in the NAc or VP, while decreasing extracellular GABA in VP (but not in NAc). AMN082 pretreatment selectively blocked cocaine-induced changes in extracellular GABA, but not in DA, in both naive rats and cocaine selfadministration rats. These data suggest: (I) mGluR7 is critically involved in cocaine's acute reinforcement; (2) GABA-, but not DA-, dependent mechanisms in the ventral striatopallidal pathway appear to underlie AMN082's actions; and (3) AMN082 or other mGluR7-selective agonists may be useful in the treatment of cocaine addiction.

Neuropsychopharmacology (2009) 34, 1783-1796; doi:10.1038/npp.2008.236; published online 21 January 2009
\end{abstract}

Keywords: mGluR7; AMN082; cocaine; dopamine; GABA; self-administration

\section{INTRODUCTION}

Glutamate is an important CNS target acted upon by cocaine and other addictive drugs (Kalivas, 2004; Wolf et al, 2004). Current glutamate-based medication development strategies for the treatment of addiction have largely targeted metabotropic glutamate receptors (mGluRs), in particular the group I (mGluR1/5) or group II (mGluR2/3) receptor subtypes (Marino and Conn, 2002; Kenny and Markou, 2004). In contrast, the group III (mGluR4/6/7/8) receptor subtypes are the least investigated due to the lack of group III mGluR subtype-selective pharmacological agents.

Previous studies have shown that intracranial microinjection of L-AP4, a non-selective group III mGluR agonist

\footnotetext{
*Correspondence: Dr Zheng-Xiong Xi, Chemical Biology Research Branch, Intramural Research Program, National Institute on Drug Abuse, Baltimore, MD 21224, USA, Tel: +443740 2517, Fax: + 443740 278I, E-mail: zxi@intra.nida.nih.gov

Received 9 September 2008; revised 20 December 2008; accepted 22 December 2008
}

(Yang, 2005), significantly lowers extracellular dopamine (DA) and glutamate in the nucleus accumbens (NAc) (Hu et al, 1999; Xi et al, 2003b), and attenuates cocaineor amphetamine-induced increases in locomotion and striatal DA (Mao et al, 2000; Mao and Wang, 2000; David and Abraini, 2003). However, studies with L-AP4 are problematic due to L-AP4's difficulty in penetrating the blood-brain barrier (Yang, 2005).

Recent development of AMN082, a systemically active metabotropic glutamate receptor 7 (mGluR7) agonist (Mitsukawa et al, 2005), makes it possible to study mGluR7 actions in psychostimulant addiction. Among the group III mGluRs, mGluR7 has the highest density in reward-related brain regions, such as striatum, NAc, ventral pallidum (VP), amygdala, and olfactory bulb (Bradley et al, 1998; Corti et al, 1998; Kinoshita et al, 1998). In addition, mGluR7 is the most highly conserved receptor subtype among all mGluRs across mammalian species (Ferraguti and Shigemoto, 2006), suggesting that an effective mGluR7 agent in experimental animals is likely to be effective at human levels. AMN082 is a potent $\left(\mathrm{EC}_{50}=64-290 \mathrm{nM}\right)$ and selective (30- to 150 -fold 
selectivity for mGluR7 over other mGluRs and NMDA receptors) allosteric agonist (Mitsukawa et al, 2005). Systemic administration of AMN082 has been shown to increase blood stress-hormone levels (Mitsukawa et al, 2005), produce antidepressant-like effects (Palucha et al, 2007), and facilitate extinction of aversive memories (Fendt et al, 2007). Deletion of mGluR7s increases seizure susceptibility (Sansig et al, 2001), reduces anxiety-like behavior, and impairs working memory (Cryan et al, 2003; Callaerts-Vegh et al, 2006), suggesting potential involvement of mGluR7s in neuropsychiatric diseases.

We have recently reported that systemic or intra-NAc administration of AMN082 modulates NAc GABA and glutamate release, but fails to alter extracellular DA (Li et al, 2008). Given the important role of NAc GABA and glutamate in cocaine reward and addiction (Kalivas, 2004; $\mathrm{Xi}$ and Gardner, 2008), we hypothesized that mGluR7s located on the NAc-VP GABAergic projection pathway may modulate cocaine's action by a mechanism downstream of NAc DA transmission. In this study, we first observed the effects of systemic or local administration of AMN082 and/ or 6-(4-methoxyphenyl)-5-methyl-3-pyridin-4-ylisoxazolo[4,5-c]pyridin-4(5H)-one (MMPIP), a selective allosteric mGluR7 antagonist that might share the same binding site with AMN082 (Suzuki et al, 2007), into the NAc-VP pathway on cocaine-enhanced brain-stimulation reward (BSR) and intravenous cocaine self-administration. In addition, we also observed the effects of AMN082 on oral sucrose self-administration, basal or cocaine-enhanced locomotion, and rotarod performance. Finally, in vivo microdialysis was used to observe the effects of AMN082 on cocaine-induced changes in extracellular DA and GABA in the NAc and VP.

\section{MATERIALS AND METHODS}

\section{Animals}

Experimentally naive male Long-Evans rats (Charles River Laboratories, Raleigh, NC, USA) weighing 250-300 g were used. They were housed individually in a climate-controlled room on a reversed light-dark cycle (lights on at 1900 hours, lights off at 0700 hours) with free access to food and water. The animal facility was fully accredited by the Association for Assessment and Accreditation of Laboratory Animal Care International. All experimental procedures were conducted in accordance with the Guide for the Care and Use of Laboratory Animals of the US National Academy of Sciences, and were approved by the Animal Care and Use Committee of the National Institute on Drug Abuse of the US National Institutes of Health.

\section{Experiment 1: Intracranial Electrical Brain-Stimulation Reward}

The general procedures for electrical BSR were as we have reported earlier (Xi et al, 2006b). Briefly, rats were anesthetized under sodium pentobarbita $(65 \mathrm{mg} / \mathrm{kg}$ i.p.), and unilateral monopolar stainless steel-stimulating electrodes (Plastics One, Roanoke, VA, USA) were surgically placed into the lateral hypothalamus $(\mathrm{AP}-2.56, \mathrm{ML} \pm 1.9$, and $\mathrm{DV}-8.6$, according to the rat brain stereotaxic atlas of
Paxinos and Watson, 1998). After 7 days recovery from surgery, rats were allowed to self-train (autoshape) to leverpress for rewarding BSR. Following establishment of leverpressing for BSR, animals were presented with a series of 16 different pulse frequencies, ranging from 141 to $25 \mathrm{~Hz}$ in descending order. Throughout the experiment, animals were run for three sessions per day. As lever-pressing behavior was variable during the first session (the 'warm up' session), but was stable during the second and third sessions, the data from the first session were discarded, and the data from the second and third sessions were designated as the baseline session data and test session data, respectively.

The BSR threshold $\left(\theta_{0}\right)$ was defined as the minimum frequency at which the animal responded for rewarding stimulation. $Y_{\max }$ was defined as the maximal rate of response. The BSR threshold $\left(\theta_{0}\right)$ and $Y_{\max }$ were mathematically derived for each baseline run and each test session run by analyzing each rate-frequency BSR function generated by a given animal over a given descending series of pulse frequencies using best-fit mathematical algorithms as reported earlier (Xi et al, 2006b).

Once stable baseline $\theta_{0}$ and $Y_{\max }$ values were achieved ( $<10 \%$ variation over five continuous days), the effects of cocaine and/or AMN082 on BSR were assessed. On test days, animals randomly received one of four different doses of AMN082 $(1,3,10,20 \mathrm{mg} / \mathrm{kg}$, i.p.) or vehicle $(0.5 \%$ Tween 80) $30 \mathrm{~min}$ before a cocaine injection $(2 \mathrm{mg} / \mathrm{kg}$, i.p.). After each test, animals received an additional 5-7 days of BSR restabilization until a new baseline $\theta_{0}$ was established. The order of testing for various doses of AMN082 was counterbalanced according to a Latin square design. The effect of AMN082 on cocaine-enhanced BSR was evaluated by comparing cocaine-induced alterations in $\theta_{0}$ value in the presence or absence of each AMN082 dose.

\section{Experiment 2: Cocaine Self-Administration}

Intravenous (i.v.) catheterization surgery and cocaine selfadministration protocols were as described earlier (Xi et al, 2006b). Briefly, i.v. catheterization was performed under sodium pentobarbital $(60 \mathrm{mg} / \mathrm{kg}$, i.p.) anesthesia with aseptic surgical technique. To determine loci of action in rat brain, additional groups of rats were also surgically implanted with intracranial guide cannulae $(20-\mathrm{G}, 14 \mathrm{~mm}$; Plastics One, Roanoke, VA, USA) into the NAc (AP + $1.7 \mathrm{~mm}, \mathrm{ML} \pm 2.0 \mathrm{~mm}, \mathrm{DV}-5.0 \mathrm{~mm}, 6^{\circ}$ angle from vertical), VP (AP $-0.24 \mathrm{~mm}, \mathrm{ML} \pm 3.2 \mathrm{~mm}, \mathrm{DV}-6.5 \mathrm{~mm}$, $6^{\circ}$ angle from vertical) or dorsal striatum (AP $2.04 \mathrm{~mm}, \mathrm{ML}$ $\pm 2.5 \mathrm{~mm}, \mathrm{DV}-3.0 \mathrm{~mm}, 6^{\circ}$ angle from vertical, according to the atlas of Paxinos and Watson, 1986). After 7 days recovery from surgery, animals were placed into standard operant chambers from MED Associates Inc. (Saint Albans, VT, USA) for cocaine self-administration $(0.5 \mathrm{mg} / \mathrm{kg}$ per infusion) under FR2 reinforcement. To avoid cocaine overdose during the self-administration period, each animal was limited to a maximum of 50 cocaine injections per $3 \mathrm{~h}$ session.

Effects of AMN082 on cocaine self-administration under FR2 reinforcement. After stable cocaine-maintained responding was achieved (ie, less than $10 \%$ variability in 
inter-response interval and less than $10 \%$ variability in active lever presses for at least 3 consecutive days), each rat without an intracranial guide cannula randomly received one of four doses of $\operatorname{AMN082}(1,3,10,20 \mathrm{mg} / \mathrm{kg}$, i.p.) or vehicle $(0.5 \%$ Tween 80$) 30 \mathrm{~min}$ prior to the test session. Animals then received an additional 5-7 days of selfadministration of cocaine alone until baseline response rate was re-established prior to testing the next dose of AMN082 or vehicle. The order of testing for the various doses of AMN082 or vehicle was counterbalanced according to a Latin square design. Rats with intracranial guide cannulae randomly received a local administration of the vehicle, AMN082 (1, 3, $5 \mu \mathrm{g} / \mu \mathrm{l}$ per side), MMPIP $(5 \mu \mathrm{g} / \mu \mathrm{l}$ per side) or the combination of AMN082 $(5 \mu \mathrm{g} / \mu \mathrm{l})$ and MMPIP $(5 \mu \mathrm{g} / \mu \mathrm{l})$ into the NAc, VP or dorsal striatum, $30 \mathrm{~min}$ prior to the test session.

After the microinjection experiments were completed, rats were anesthetized with a high dose of pentobarbital ( $>100 \mathrm{mg} / \mathrm{kg}$ i.p.) and perfused transcardially with $0.9 \%$ saline followed by $10 \%$ formalin. Brains were removed and placed in $10 \%$ formalin for histological verification of microinjection locations.

Effects of AMN082 on cocaine self-administration under $P R$ reinforcement. Initial cocaine self-administration under FR2 reinforcement schedules was identical to that outlined above. After stable cocaine self-administration under FR2 reinforcement was established, the subjects were switched to cocaine self-administration $(0.5 \mathrm{mg} / \mathrm{kg}$ per infusion) under a progressive-ratio (PR) schedule, during which the work requirement (lever presses) needed to receive a single i.v. cocaine infusion was progressively raised within each test session (see details in Richardson and Roberts, 1996; Xi et al, 2006b). The break point was defined as the maximal work load (ie, number of lever presses) completed for the last cocaine infusion prior to a 1-hour period during which no infusions were obtained by the animal. Animals were allowed to continue daily sessions of cocaine self-administration under PR reinforcement conditions until day-to-day variability in break point fell within 1-2 ratio increments for 3 consecutive days. Once a stable break point was established, subjects were assigned to four subgroups to determine the effects of three different doses of AMN082 (3, $10,20 \mathrm{mg} / \mathrm{kg}$, i.p.) or vehicle $(0.5 \%$ Tween 80$)$ on PR break point for cocaine self-administration. Here, we chose a between-subjects design to determine the effects of AMN082 on PR break point, because of difficulty in re-achieving stable basal break point levels after drug tests.

\section{Experiment 3: Oral Sucrose Self-Administration}

To determine whether AMN082 selectively inhibits the rewarding effects of cocaine, we further observed the effects of AMN082 on oral sucrose self-administration (natural reward) in rats. The procedures for sucrose self-administration were identical to the procedures for cocaine self-administration except for the following: (1) no surgery was performed on the animals in the sucrose experiment; (2) active lever presses led to delivery of $0.1 \mathrm{ml}$ of $5 \%$ sucrose solution into a liquid food tray on the operant chamber wall.

\section{Experimental 4: Locomotor Activity}

Before receiving any drug, rats were placed in a locomotor detection chamber (AccuScan, Columbus, OH, USA) to record baseline locomotor activity for $1 \mathrm{~h}$. Rats were then divided into two groups. One group of rats randomly received either the vehicle $(1 \mathrm{ml} / \mathrm{kg} 0.5 \%$ Tween 80$)$ or one AMN082 dose $(10,20 \mathrm{mg} / \mathrm{kg}$, i.p.) to determine whether AMN082 alone alters basal levels of locomotion. Another group of rats received either the vehicle or one AMN082 dose $(10,20 \mathrm{mg} / \mathrm{kg}$, i.p., $30 \mathrm{~min}$ prior to a cocaine injection) to determine whether AMN082 pretreatment alters cocaine (10 mg/kg, i.p.)-induced hyperlocomotion. The order of testing for various doses of AMN082 was counterbalanced according to a Latin square design. Following the injection, locomotor activity was recorded for $3 \mathrm{~h}$ in $10 \mathrm{~min}$ bins, and distance counts were used to evaluate the effects of AMN082 on basal levels of locomotion or cocaine-induced hyperlocomotion.

\section{Experiment 5: Rotarod Performance}

To further determine whether AMN082 causes locomotor impairment or alters motivated locomotion, we observed the effects of systemic or local administration of AMN082 into the NAc or VP on rat rotarod performance. Performance on an accelerating rotarod was assessed using a fourstation rat rotarod (AccuScan Instruments Inc., Columbus, $\mathrm{OH}$, USA). The speed of rotation of the rotarod was increased from 2.5 to 40 r.p.m. over $2 \mathrm{~min}$ and the time (s) the animal remained on the rod was determined as the mean of three trials. After 5-7 days of habituation and training on the rotarod device, three groups of rats randomly received either the vehicle or one dose $(10,20 \mathrm{mg} /$ $\mathrm{kg}$, i.p.) of AMN082 before the rotarod test began. For rats with intracranial guide cannula implantation, either the vehicle or AMN082 $(5 \mu \mathrm{g} / \mu \mathrm{l}$ per side) was locally injected into the NAc or VP. After the drug injection, animals were placed on the rotarod device to observe their locomotor performance over $30 \mathrm{~min}$ intervals for a total duration of $3 \mathrm{~h}$.

\section{Experiment 6: In Vivo Microdialysis with HPLC}

In vivo microdialysis protocols were as reported earlier (Xi et al, 2006a). Briefly, rats were anesthetized with sodium pentobarbital, and guide cannulae (20-G, Plastics One, Roanoke, VA, USA) were surgically implanted into the NAc $\left(\mathrm{AP}+1.7 \mathrm{~mm}, \mathrm{ML} \pm 2.0 \mathrm{~mm}, \mathrm{DV}-4.0 \mathrm{~mm}, 6^{\circ}\right.$ from vertical $)$ or VP (AP $-0.3 \mathrm{~mm}, \mathrm{ML} \pm 3.2 \mathrm{~mm}, \mathrm{DV}-5.5 \mathrm{~mm}, 6^{\circ}$ angle from vertical), according to the rat brain atlas of Paxinos and Watson (1998). The guide cannulae were fixed to the skull with four stainless steel jeweler's screws (Small Parts Inc., Miami Lakes, FL, USA) and dental acrylic. After 7 days of recovery from surgery, rats were divided into two groups. One group of rats (drug-naive rats) were used directly for in vivo microdialysis, whereas another group of rats were trained for cocaine self-administration first and then used for in vivo microdialysis beginning at $24 \mathrm{~h}$ after the last cocaine self-administration. Microdialysis probes were inserted into the NAc $12 \mathrm{~h}$ before the onset of microdialysis to minimize damage-induced neurotransmitter release. Microdialysis samples were collected every $20 \mathrm{~min}$ into 
$10 \mu \mathrm{l} 0.5 \mathrm{M}$ perchloric acid to prevent DA degradation. After collection, samples were frozen at $-80^{\circ} \mathrm{C}$. Dialysate DA and GABA were measured using high pressure liquid chromatography (HPLC) with electrochemical and flourometric detection, respectively, as reported earlier (Xi et al, 2006a). DA and GABA values were quantified with external standard curves (DA 0.1-1.0 nM; GABA 10-1000 nM). The limits of detection for DA and GABA were $0.01-10 \mathrm{nM}$ and $1 \mathrm{nM}-10 \mu \mathrm{M}$, respectively.

After microdialysis experiments were completed, rats were anesthetized with a high dose of pentobarbital ( $>100 \mathrm{mg} / \mathrm{kg}$ i.p.) and perfused transcardially with $0.9 \%$ saline followed by $10 \%$ formalin. Brains were removed and placed in $10 \%$ formalin for histological verification of microdialysis probe locations in rat brain.

\section{Drugs}

Cocaine $\mathrm{HCl}$ (Sigma Chemical Co., Saint Louis, MO, USA) was dissolved in physiological saline. We used different doses of cocaine in the BSR $(2 \mathrm{mg} / \mathrm{kg}$, i.p.), locomotion and microdialysis experiments (3-10 mg/kg, i.p.) based upon the amplitude of the biological response to cocaine or system sensitivity in detection of cocaine-induced changes in different measures. $N, N^{\prime}$-dibenzyhydryl-ethane-1,2-diamine dihydrochloride (AMN082), 6-(4-methoxyphenyl)5-methyl-3-(4-pyridinyl)-isoxazolo[4,5-c]pyridin-4(5H)-one hydrochloride (MMPIP) and tetrodotoxin (TTX) were purchased from Tocris Bioscience (Ellisville, MO, USA). For intraperitoneal (i.p.) injection, AMN082 was dissolved in $0.5 \%$ Tween 80 (Sigma-RBI, St. Louis, MO, USA). For intracranial microinjection, AMN082 or MMPIP were dissolved in $25 \%$ 2-hydroxypropyl- $\beta$-cyclodextrin (SigmaRBI, St. Louis, MO, USA). As AMN082-induced changes in extracellular NAc GABA and glutamate appeared at $20 \mathrm{~min}$ after AMN082 administration (Li et al, 2008), AMN082 was administered $30 \mathrm{~min}$ prior to cocaine in the BSR and locomotion experiments, and $40 \mathrm{~min}$ (two 20-min dialysis samples) prior to cocaine in the microdialysis study.

\section{Data Analyses}

All data are presented as means ( \pm SEM). One-way analysis of variance (ANOVA) and/or two-way ANOVA for repeated measures were used to analyze the effects of AMN082 and cocaine on behavioral and neurochemical changes. Individual group comparisons were carried out using the StudentNewman-Keuls method.

\section{RESULTS}

\section{AMN082 Attenuates Cocaine-Enhanced BSR}

Figure 1a illustrates representative rate-frequency function curves for BSR, indicating BSR threshold $\left(\theta_{0}, \mathrm{~Hz}\right)$ and $Y_{\max }$ (maximal lever presses/30s), and representative effects of
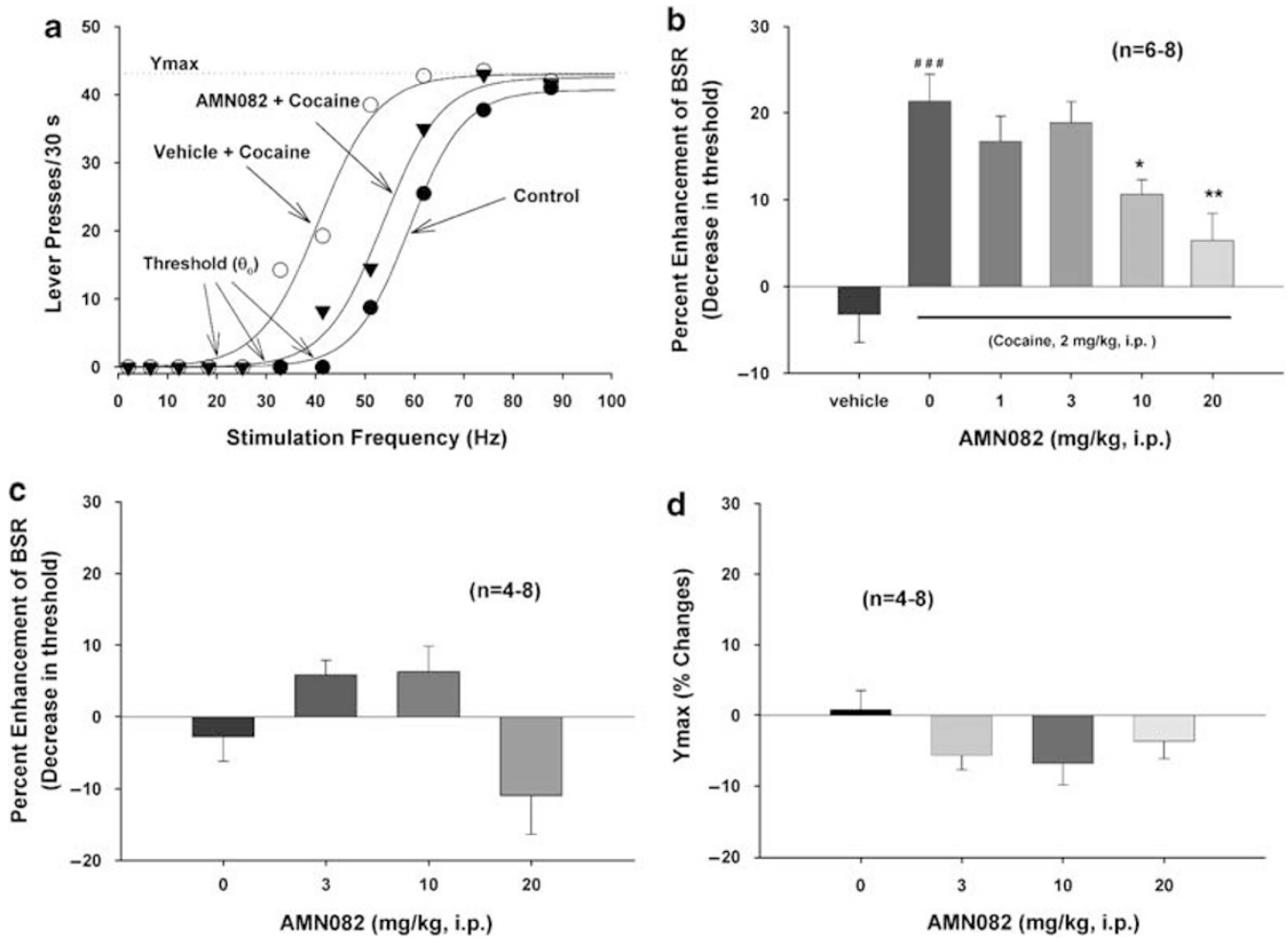

Figure I Effects of cocaine and/or AMN082 on electrical brain-stimulation reward (BSR). (a) Shows representative rate-frequency function curves for $\mathrm{BSR}$, indicating that cocaine $\left(2 \mathrm{mg} / \mathrm{kg}\right.$, i.p.) shifted the rate-frequency function curve to the left, lowering the BSR threshold $\theta_{0}$ value (ie, enhancing BSR), without a change in the $Y_{\max }$ level. Pretreatment with AMN082 $\left(20 \mathrm{mg} / \mathrm{kg}\right.$, i.p.) significantly attenuated the cocaine-enhanced BSR without changing the $Y_{\max }$ level. (b) Shows mean cocaine-enhanced BSR, and its dose-dependent attenuation by AMN082 (I-20 mg/kg, i.p.). (c and d) Show that AMN082 itself ( 3 , I0, $20 \mathrm{mg} / \mathrm{kg}$, i.p.) altered neither BSR (as assessed by threshold $\theta_{0}$ ) nor $Y_{\max }{ }^{2} \# \# p<0.00 \mathrm{I}$, when compared with the vehicle treatment group. $* p<0.05$, *** $<0.0$ I, when compared with the cocaine-alone treatment group. 
cocaine and AMN082 on BSR. Cocaine, at $2 \mathrm{mg} / \mathrm{kg}$, produced a significant enhancement of BSR, as indicated by the leftward shift in the rate-frequency function curve, reflecting lowered BSR threshold $\left(\theta_{0}\right)$ values. This cocaineenhanced BSR was substantially attenuated by AMN082 (20 mg/kg, i.p., $30 \mathrm{~min}$ prior to cocaine administration). Figure $1 \mathrm{~b}$ illustrates the mean effect of cocaine plus AMN082 on BSR threshold. One-way ANOVA for repeated measures performed on the data illustrated in Figure $1 \mathrm{~b}$ revealed a statistically significant treatment main effect $\left(\mathrm{F}_{5,33}=11.91, p<0.001\right)$. Individual group comparisons revealed that $2 \mathrm{mg} / \mathrm{kg}$ cocaine significantly enhanced electrical BSR (Vehicle vs $2 \mathrm{mg} / \mathrm{kg}$ cocaine: $q=9.41$, $p<0.001)$, an effect that was dose-dependently attenuated by $10 \mathrm{mg} / \mathrm{kg}(q=3.94, p<0.05)$ or $20 \mathrm{mg} / \mathrm{kg}$ AMN082 $(q=5.02, p<0.01)$, but not by $1 \mathrm{mg} / \mathrm{kg}(q=1.77, p=\mathrm{NS})$ or $3 \mathrm{mg} / \mathrm{kg}(q=0.96, p=\mathrm{NS})$. AMN082 alone did not significantly alter electrical BSR; individual group comparisons for the data shown in Figure 1c did not reveal significant differences between vehicle and any dose of AMN082 tested. Figure 1d illustrates that AMN082, at all doses tested, had no effect on $Y_{\max }$ levels $\left(\mathrm{F}_{3,27}=2.99\right.$, $p=\mathrm{NS})$.

\section{AMN082 Inhibits Cocaine, but not Sucrose, Self- Administration}

Figure 2a illustrates a dose-dependent inhibition of cocaine self-administration by AMN082 $\left(\mathrm{F}_{4,46}=9.92, p<0.001\right)$. Individual group comparisons revealed a statistically significant reduction in the total number of infusions during a $3 \mathrm{~h}$ session after $10 \mathrm{mg} / \mathrm{kg}(q=4.12, p<0.05)$ or $20 \mathrm{mg} / \mathrm{kg}$ AMN082 $(q=8.14, p<0.001)$, but not $1 \mathrm{mg} / \mathrm{kg} \quad(q=0.36$, $p=\mathrm{NS})$ or $3 \mathrm{mg} / \mathrm{kg}(q=2.64, p=\mathrm{NS})$, when compared with the vehicle treatment group. Figure $2 \mathrm{~b}$ illustrates mean time courses of cocaine self-administration after vehicle or AMN082. Given that the durations (time) to complete the maximal 50 cocaine infusions were variable among animals before and after AMN082 administration, we statistically analyzed the initial $80 \mathrm{~min}$ self-administration data (Figure 2b) during which time cocaine was available for self-administration for all animals tested (ie, before the software terminated the session after the maximal permitted 50 infusions). Two-way ANOVA for repeated measures over time revealed a statistically significant AMN082 treatment main effect $\left(\mathrm{F}_{4,40}=6.27, p<0.001\right)$, significant treatment $\times$ time interaction $\left(\mathrm{F}_{12,120}=2.25, p<0.05\right)$, but no significant time main effect $\left(\mathrm{F}_{3,12}=2.48, p=\mathrm{NS}\right)$. Individual group comparisons indicated that AMN082-induced reductions in cocaine self-administration were statistically significant after $3 \mathrm{mg} / \mathrm{kg}$ at $20 \mathrm{~min}(q=3.32, p<0.05)$, $10 \mathrm{mg} / \mathrm{kg}$ at $20 \mathrm{~min}(q=4.21, p<0.001), 20 \mathrm{mg} / \mathrm{kg}$ at $20 \mathrm{~min}(q=4.97, p<0.001)$ and $40 \mathrm{~min}(q=3.02, p<0.05)$, when compared with the same time point in the vehicle control group (Figure $2 b$ ). Figure $2 \mathrm{c}$ illustrates that AMN082 (3, 10 , or $20 \mathrm{mg} / \mathrm{kg}$, i.p., $30 \mathrm{~min}$ prior to testing) had no effect on oral sucrose self-administration under FR2 reinforcement $\left(F_{3,26}=0.61, p=N S\right)$. Figure $2 \mathrm{D}$ shows the mean effects of AMN082 on PR break point for cocaine selfadministration, illustrating that $\operatorname{AMN} 082(3,10,20 \mathrm{mg} / \mathrm{kg}$, i.p.) dose-dependently lowered the $P R$ break point for cocaine self-administration $\left(\mathrm{F}_{3,23}=11.17, p<0.001\right)$. Indi- vidual group comparisons revealed a statistically significant reduction in break point after $10 \mathrm{mg} / \mathrm{kg}(q=5.51, p<0.01)$ or $20 \mathrm{mg} / \mathrm{kg}$ AMN082 $(q=7.22, p<0.001)$, but not after $3 \mathrm{mg} / \mathrm{kg}$ AMN082 $(q=1.61, p=\mathrm{NS})$, when compared with the vehicle treatment group.

\section{AMN082 has No Effect on Basal or Cocaine-Enhanced Locomotion}

Figure $3 \mathrm{a}$ illustrates that AMN082, at the same doses used above, did not alter basal levels of locomotion $\left(F_{3,26}=0.79, p=\mathrm{NS}\right)$. Figure $3 \mathrm{~b}$ illustrates that AMN082 also failed to alter cocaine-induced increases in locomotion $\left(F_{2,21}=2.23, p=\mathrm{NS}\right)$.

Systemic Administration of AMN082 Inhibits, Whereas Intracranial Microinjection of AMN082 Failed to Alter Rotarod Performance

Figure $3 c$ illustrates that systemic administration of AMN082, at $20 \mathrm{mg} / \mathrm{kg}$ but not $10 \mathrm{mg} / \mathrm{kg}$, significantly inhibited rotarod performance. Two-way ANOVA for repeated measures over time revealed a statistically significant treatment main effect $\left(\mathrm{F}_{2,21}=4.28, p<0.05\right)$, time main effect $\left(\mathrm{F}_{5,10}=5.03, p<0.001\right)$, and treatment $\times$ time interaction $\left(\mathrm{F}_{10,105}=2.03, p<0.05\right)$. Individual group comparisons revealed a statistically significant reduction in rotarod performance after $20 \mathrm{mg} / \mathrm{kg}$ AMN082 at $30 \mathrm{~min}(q=3.67, p<0.05)$ and $60 \mathrm{~min}(q=4.16, p<0.05)$, but not at other time points after $20 \mathrm{mg} / \mathrm{kg}$ AMN082 nor at any time points after $10 \mathrm{mg} / \mathrm{kg}$ AMN082, when compared with the same time point in the vehicle control group. Figure $3 \mathrm{~d}$ illustrates that microinjection of AMN082 $(5 \mu \mathrm{g} / \mu \mathrm{l}$ per side) into the NAc $\left(\mathrm{F}_{1,8}=0.059, p=\mathrm{NS}\right)$ or the VP $\left(\mathrm{F}_{1,8}=0.01, p=\mathrm{NS}\right)$ did not alter rotarod performance.

\section{Intra-NAc or Intra-VP, but not Intra-Dorsal Striatum, Administration of AMN082 Inhibits Cocaine Self- Administration}

Figure 4 illustrates that microinjections of $\operatorname{AMN} 082(1,3$, $5 \mu \mathrm{g} / \mu \mathrm{l}$ per side) into the NAc (Figure $4 \mathrm{a}, \mathrm{F}_{3,27}=6.56$, $p<0.01$ ) or VP (Figure $4 \mathrm{~b}, \mathrm{~F}_{3,22}=34.11, p<0.001$ ), but not dorsal striatum (Figure $4 c, \mathrm{~F}_{2,15}=1.02, p=\mathrm{NS}$ ), dose-dependently inhibited cocaine self-administration under FR2 reinforcement. Individual group comparisons revealed a statistically significant inhibition of cocaine self-administration after $3 \mu \mathrm{g}$ (Figure $4 \mathrm{a}: q=4.62, p<0.01$; Figure 4b: $q=9.97, p<0.001$ ) or $5 \mu$ g AMN082 (Figure $4 \mathrm{a}$ : $q=5.32, p<0.01$; Figure 4b: $q=10.03, p<0.001$ ), but not $1 \mu \mathrm{g}$ (Figure 4a: $q=0.24, p=\mathrm{NS}$; Figure 4b: $q=1.25$, $p=\mathrm{NS}$ ) into the NAc or VP, when compared with the vehicle treatment group.

Intra-NAc or Intra-VP Administration of MMPIP Blocks AMN082-Induced Inhibition of Cocaine SelfAdministration

Figure 5A illustrates that intra-NAc microinjection of AMN082 $(5 \mu \mathrm{g} / \mu \mathrm{l}$ per side) significantly inhibited cocaine self-administration, an effect that was partially blocked by intra-NAc co-administration of MMPIP $\left(\mathrm{F}_{3,24}=11.16\right.$, 

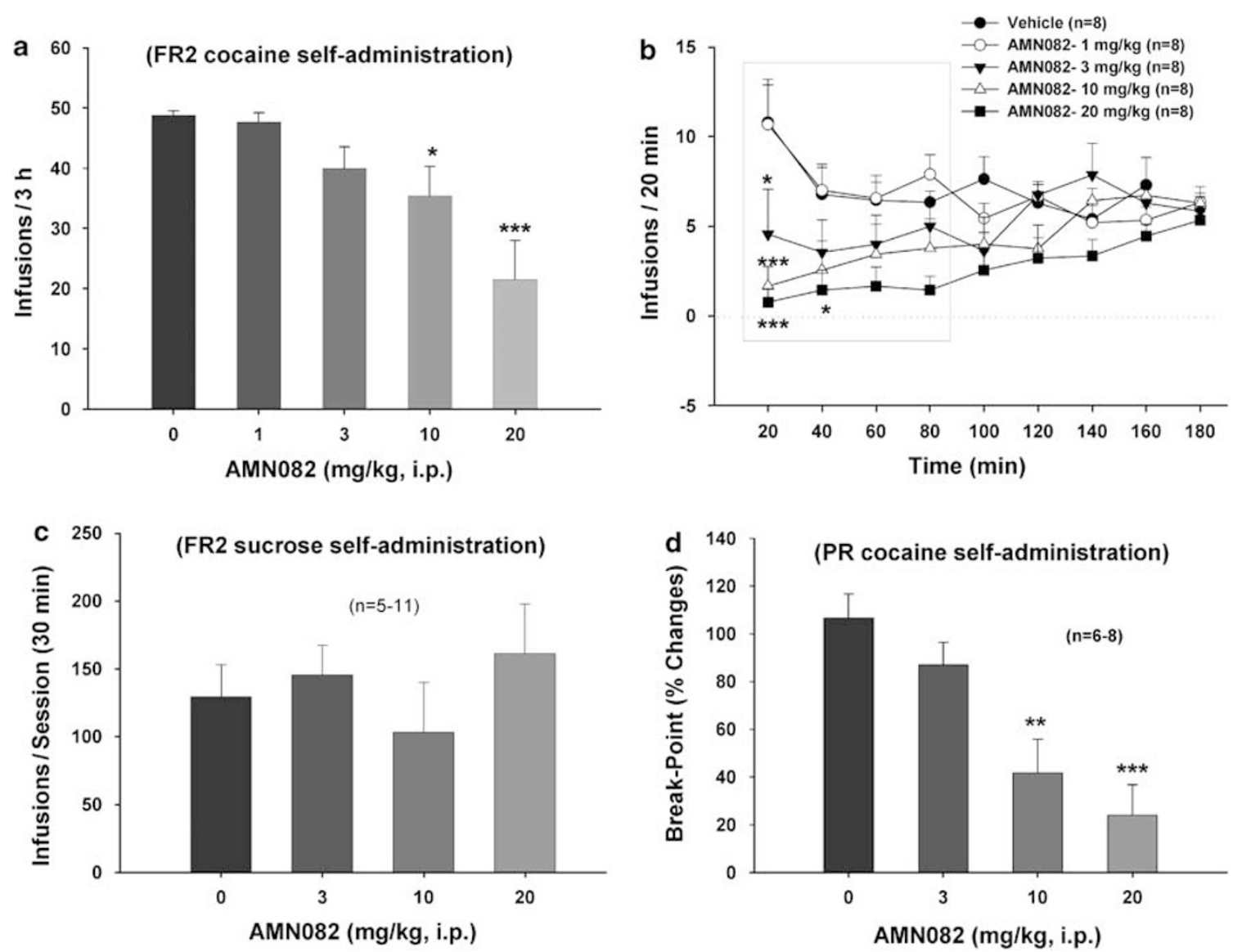

Figure 2 Effects of AMN082 on cocaine or sucrose self-administration. (a) Shows total number of cocaine infusions during the $3 \mathrm{~h}$ cocaine selfadministration under FR2 reinforcement after each dose of AMN082. (b) Shows the mean time courses of cocaine self-administration after each dose of AMN082 administration. (c) Shows total numbers of infusions during 30 min sucrose self-administration after each dose of AMN082. (d) Shows mean break point levels after AMN082 administration, illustrating that $\operatorname{AMN082~(3,10,20~mg/kg,~i.p.)~dose-dependently~lowered~the~break~point~for~cocaine~self-~}$ administration under PR reinforcement conditions. $* p<0.05$, $* * 00.05$, **** $p<0.00$ I, when compared with the vehicle control group (a, d) or the same time point in the vehicle control group (b).

$p<0.001)$. Individual group comparisons revealed a statistically significant difference between Veh + Veh and Veh + AMN $(q=7.63, p<0.001), \mathrm{Veh}+\mathrm{Veh}$ and MMPIP $+\mathrm{AMN}$ $(q=3.84, p<0.05)$, or Veh + AMN and MMPIP + AMN $(q=4.05, p<0.01)$. MMPIP alone $(5 \mu \mathrm{g} / \mu \mathrm{l}$ per side $)$ had no effect on cocaine self-administration $(q=1.20, p=\mathrm{NS})$, when compared to the vehicle treatment group. Figure $5 \mathrm{~b}$ illustrates that intra-VP microinjection of AMN082 $(5 \mu \mathrm{g} / \mu \mathrm{l}$ per side) also inhibited cocaine self-administration and that this was partially blocked by intra-VP co-administration of MMPIP $\left(5 \mu \mathrm{g} / \mu \mathrm{l}\right.$ per side) $\left(\mathrm{F}_{3,20}=13.64, p<0.001\right)$. Individual group comparisons revealed a significant reduction in cocaine self-administration after AMN082 (Veh + Veh vs Veh + AMN: $q=7.28, p<0.001)$, but not after MMPIP coadministration (Veh + Veh $v s$ MMPIP + AMN: $q=1.04$, $p=\mathrm{NS}$; Veh + AMN vs MMPIP + AMN: $q=6.86, p<0.001)$. Intra-VP microinjection of MMPIP alone $(5 \mu \mathrm{g} / \mu \mathrm{l}$ per side) failed to alter cocaine self-administration (Veh + Veh $v s$ MMPIP + Veh: $q=1.82, p=\mathrm{NS}$ ).

\section{AMN082 has no Effect on Cocaine-Enhanced NAc DA}

Figure 6a illustrates that AMN082, when administered systemically $(3,10,20 \mathrm{mg} / \mathrm{kg}$ i.p.), failed to alter basal levels of extracellular NAc DA. Two-way ANOVA for repeated measurements over time revealed no statistically significant treatment (AMN082 vs vehicle) main effect $\left(\mathrm{F}_{3,25}=0.62\right.$, $p=\mathrm{NS})$, nor time main effect $\left(\mathrm{F}_{11,275}=0.45, p=\mathrm{NS}\right)$. Figure $6 \mathrm{~b}$ shows that acute cocaine $(10 \mathrm{mg} / \mathrm{kg}$, i.p.) produced a significant increase $(\sim 300 \%)$ in extracellular NAc DA. Pretreatment with AMN082 (10, $20 \mathrm{mg} / \mathrm{kg})$ failed to alter cocaine-enhanced NAc DA. Two-way ANOVA for repeated measurements over time revealed a statistically significant time main effect $\left(\mathrm{F}_{8,160}=33.63, p<0.001\right)$, but no significant treatment main effect $\left(\mathrm{F}_{2,20}=1.26, p=\mathrm{NS}\right)$, nor a treatment $\times$ time interaction $\left(\mathrm{F}_{16,160}=0.57, p=\mathrm{NS}\right)$. Individual group comparisons revealed that the cocaineinduced increases in NAc DA in each group were statistically significant, whereas AMN082 pretreatment had no effect on cocaine-enhanced NAc DA.

\section{AMN082 has no Effect on Cocaine-Enhanced VP DA}

Figure 7 illustrates that systemic administration of AMN082 $(10,20 \mathrm{mg} / \mathrm{kg}$, i.p.) failed to alter cocaine-induced increase of extracellular VP DA either in naive rats or in cocaine self-administration experienced rats. Two-way ANOVA for repeated measures over time for the data shown in Figure $7 \mathrm{a}$ 

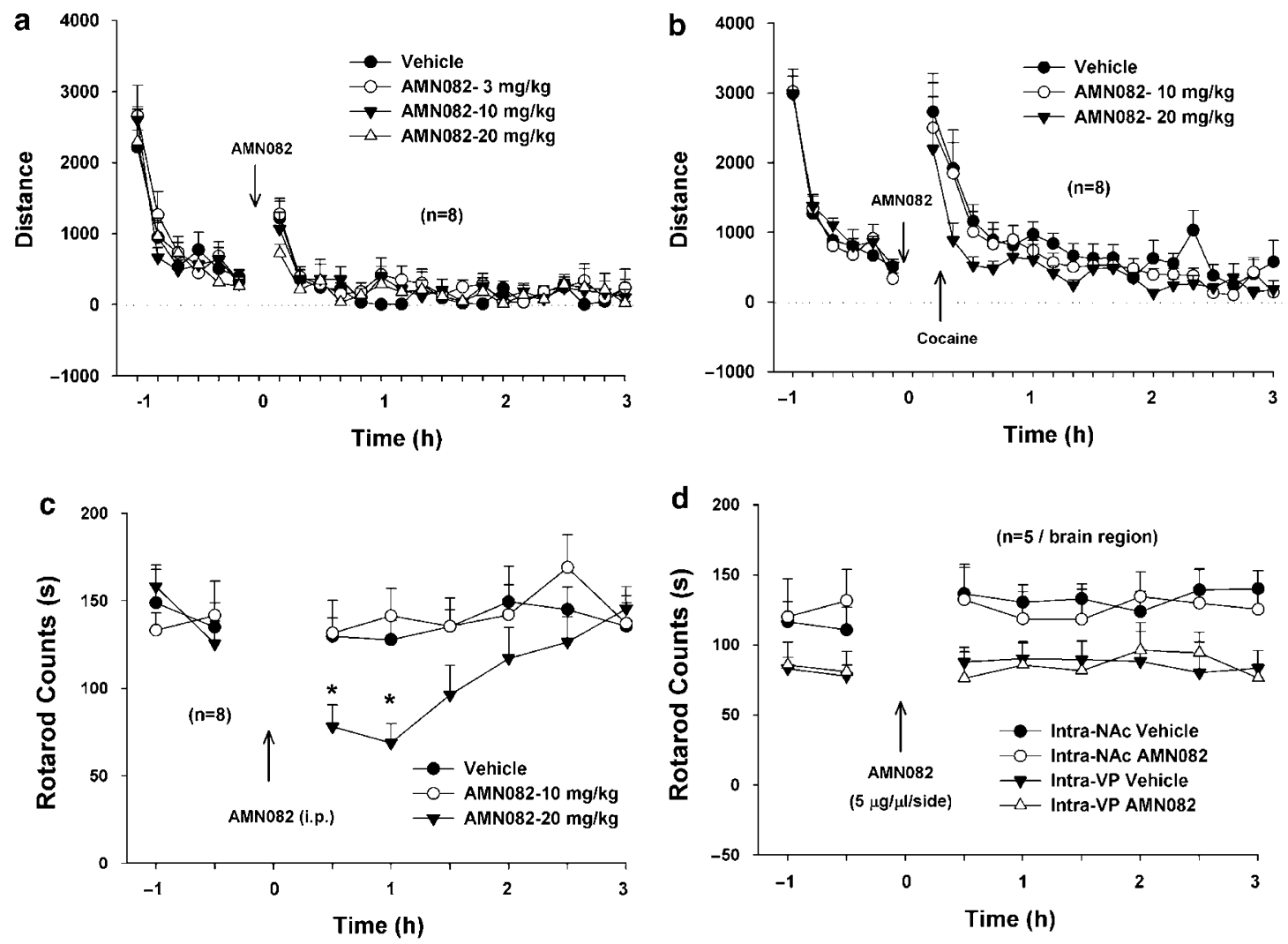

Figure 3 Effects of AMN082 on locomotion and rotarod performance in rats. (a) Shows that AMN082 (3-20 mg/kg, i.p.) had no effect on basal levels of locomotor activity. (b) Shows that AMN082 ( $10-20 \mathrm{mg} / \mathrm{kg}$, i.p.) had no significant effect on cocaine-induced increases in locomotion. (c) Shows that systemic administration of AMN082, at $20 \mathrm{mg} / \mathrm{kg}$, but not $10 \mathrm{mg} / \mathrm{kg}$, significantly inhibited rotarod performance, an effect that lasted for about I h. (d) Shows that local intra-NAc or intra-VP administration of AMN082 $\left(5 \mu \mathrm{g} / \mu \mathrm{l}\right.$ per side) failed to alter rotarod performance. ${ }^{*} p<0.05$, when compared with the same time point in the vehicle control group.

a (Intra-NAc)
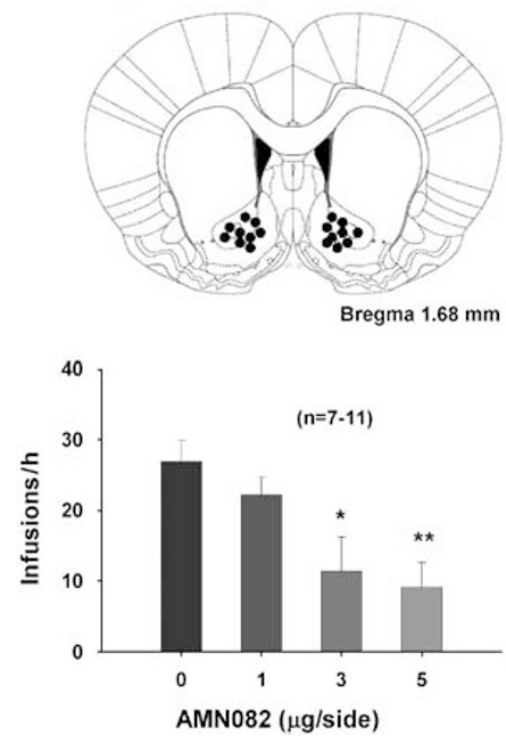

b
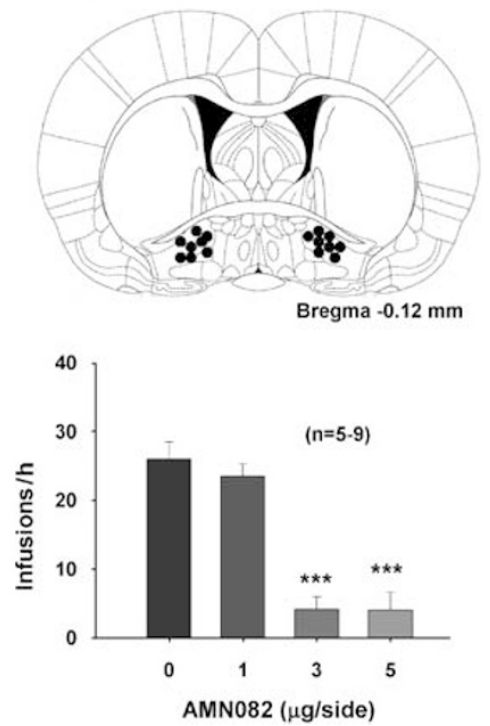

C (Intra-dorsal striatum)
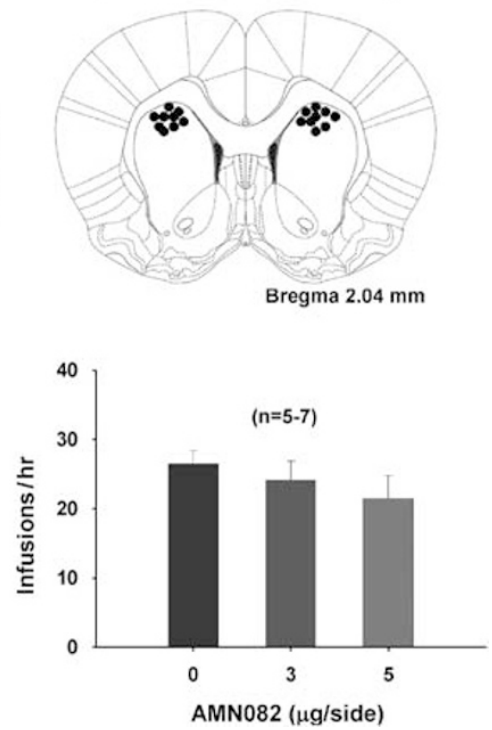

Figure 4 Effects of microinjection of AMN082 into the NAc, VP or dorsal striatum on cocaine self-administration under FR2 reinforcement.

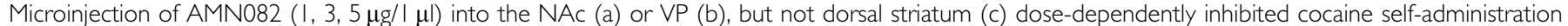
under FR2 reinforcement. $* p<0.05$, $* * p<0.01$, **** $p<0.00$ I, compared to vehicle treatment group.

revealed only a significant time main effect $\left(\mathrm{F}_{11,253}=65.86\right.$, $p<0.001)$, but no significant treatment main effect $\left(\mathrm{F}_{2,23}=0.38, \quad p=\mathrm{NS}\right)$, nor significant treatment $\times$ time interaction $\left(\mathrm{F}_{22,253}=0.98, p=\mathrm{NS}\right)$. Similarly, two-way ANOVA for repeated measures over time for the data shown in Figure $7 \mathrm{~b}$ revealed only a statistically significant 

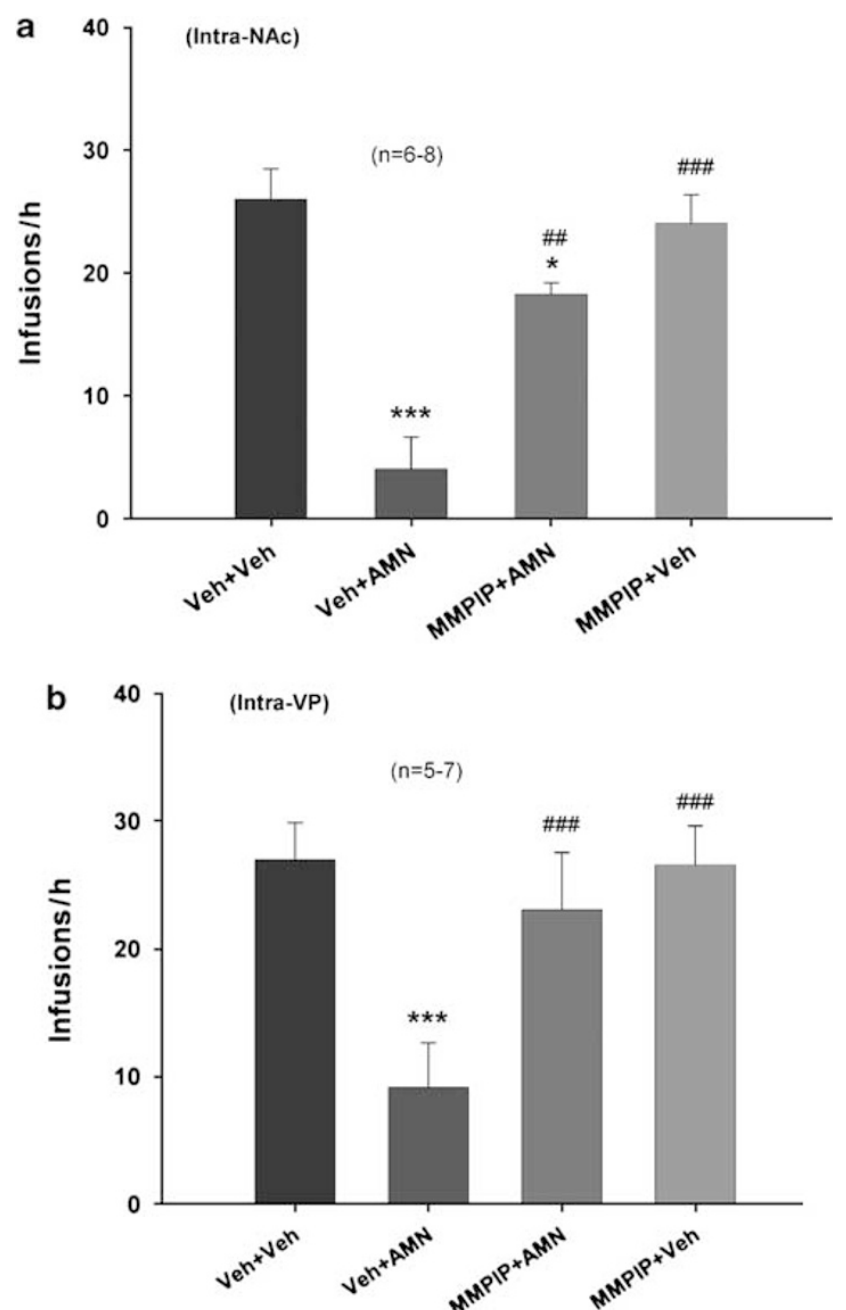

Figure 5 Effects of microinjection of MMPIP into the NAc or VP on AMN082-induced inhibition of cocaine self-administration. Co-administration of MMPIP ( $5 \mu \mathrm{g} / \mu \mathrm{l}$ per side) with AMN082 (5 $\mu \mathrm{g} / \mu \mathrm{l}$ per side) into the NAc (a) or VP (b) significantly blocked AMN082-induced inhibition of cocaine self-administration under an FR2 reinforcement schedule. MMPIP ( $5 \mu \mathrm{g} / \mu \mathrm{l}$ per side) alone had no effect when administered either into the NAc (a) or VP (b). $* p<0.05$, **** $p<0.00$ I, compared to vehicle treatment

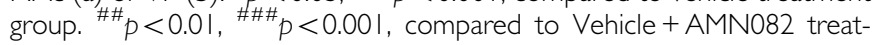
ment group.

time main effect $\left(F_{11,198}=55.07, p<0.001\right)$, but no significant treatment main effect $\left(\mathrm{F}_{2,18}=0.08, p=\mathrm{NS}\right)$, nor significant treatment $\times$ time interaction $\left(\mathrm{F}_{22,198}=0.75\right.$, $p=\mathrm{NS})$. Figure 7c illustrates that AMN082 $(10,20 \mathrm{mg} / \mathrm{kg}$ i.p.) alone failed to alter basal levels of extracellular DA levels in the VP in drug naive rats $\left(\mathrm{F}_{2,19}=0.45, p=\mathrm{NS}\right)$. Table 1 shows the mean basal levels of extracellular VP DA (over three baseline values before AMN082 and/or cocaine administration), illustrating that basal levels of extracellular DA did not differ between the vehicle group and any AMN082 dose group.

\section{Systemic Cocaine Inhibits Neuronal GABA Release in the VP}

Figure $8 \mathrm{a}$ illustrates that cocaine dose-dependently decreased extracellular VP GABA levels. Two-way ANOVA for repeated measures revealed a statistically significant treatment main effect $\left(\mathrm{F}_{2,20}=7.79, p<0.05\right)$, time main effect $\left(\mathrm{F}_{11,264}=3.21, \quad p<0.001\right)$, and treatment $\times$ time interaction $\left(\mathrm{F}_{22,264}=2.61, p<0.001\right)$. Individual group comparisons revealed a significant reduction in VP GABA levels after $10 \mathrm{mg} / \mathrm{kg}(q=3.82, p<0.05)$, but not after $3 \mathrm{mg} /$ $\mathrm{kg}(q=0.88, p=\mathrm{NS})$ cocaine. Figure $8 \mathrm{~b}$ illustrates that intra-VP perfusion of tetrodotoxin (TTX) did not significantly alter extracellular VP GABA levels, but blocked cocaine-induced reduction in VP GABA release. Two-way ANOVA over time revealed a significant treatment main effect $\left(\mathrm{F}_{2,17}=4.43, p<0.05\right)$, time main effect $\left(\mathrm{F}_{11,231}=5.86\right.$, $p<0.001)$, and treatment $\times$ time interaction $\left(\mathrm{F}_{22,231}=2.45\right.$, $p<0.001)$. Individual group comparisons indicated that intra-VP TTX attenuated cocaine-induced reduction in VP $\mathrm{GABA}$ at all post-cocaine time points starting at $40 \mathrm{~min}$.

\section{AMN082 Blocks the Cocaine-Induced Reduction in VP GABA Release}

Figure 9a illustrates that pretreatment with AMN082 $(10,20 \mathrm{mg} / \mathrm{kg}$, i.p., $40 \mathrm{~min}$ prior to cocaine) significantly blocked cocaine's inhibitory effect on extracellular VP GABA in drug naive rats $\left(\mathrm{F}_{2,19}=8.49, p<0.001\right)$. Individual group comparisons revealed a significant attenuation of cocaine's inhibitory effect on extracellular VP GABA after $10 \mathrm{mg} / \mathrm{kg}(q=3.87, p<0.05)$ or $20 \mathrm{mg} / \mathrm{kg}(q=5.66, p<0.01)$ AMN082. Figure $9 \mathrm{~b}$ illustrates that pretreatment with the same doses of AMN082 also significantly attenuated the cocaine-induced reduction in VP GABA release in rats measured $24 \mathrm{~h}$ after the last cocaine self-administration session. Two-way ANOVA for repeated measures over time revealed no significant treatment main effect $\left(\mathrm{F}_{2,24}=0.97\right.$, $p=\mathrm{NS}$ ), but a statistically significant time main effect $\left(\mathrm{F}_{11,264}=2.68, p<0.01\right)$ and treatment $\times$ time interaction $\left(\mathrm{F}_{22,264}=1.89, p<0.05\right)$. One-way ANOVA for repeated measures over time for each AMN082 treatment group revealed a statistically significant reduction in VP GABA release after cocaine only in the vehicle treatment group $\left(\mathrm{F}_{11,110}=5.41, p<0.001\right)$, but not in the AMN082 treatment groups. Figure $9 \mathrm{c}$ illustrates that systemic administration of AMN082 by itself did not alter extracellular VP GABA levels $\left(\mathrm{F}_{2,20}=0.89, p=\mathrm{NS}\right)$.

Table 1 shows the mean basal levels of extracellular VP GABA (over three baseline values measured before drug administration), illustrating that basal levels of extracellular GABA did not differ between the vehicle group and any AMN082 dose group. However, basal extracellular VP GABA levels were significantly lower in cocaine self-administration rats than in naive rats (vehicle in naive rats $v s$ vehicle in cocaine self-administration rats, $t=2.5$, $p<0.05)$.

\section{Histology}

Figure 10 depicts microdialysis probe locations, demonstrating that the microdialysis probe active membranes were located within the NAc core and shell (left panels) and the VP (right panels), respectively. There were no obvious differences in microdialysis probe placement across the different experimental groups. 

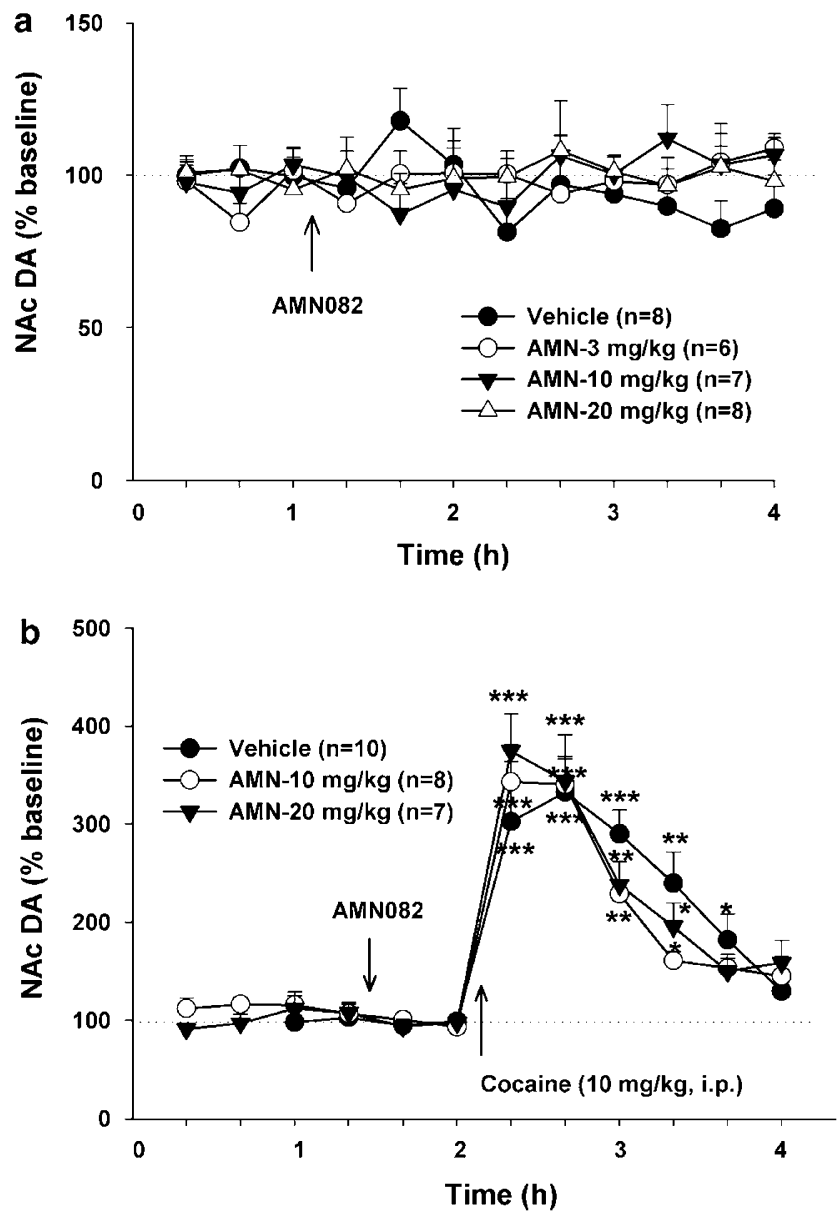

Figure 6 Effects of AMN082 on basal or cocaine-enhanced extracellular NAc DA. (a) Illustrates the fact that AMN082 (3, 10, $20 \mathrm{mg} / \mathrm{kg}$, i.p.) alone did not alter extracellular NAc DA. (b) Illustrates the fact that pretreatment with $A M N 082(10,20 \mathrm{mg} / \mathrm{kg}$, i.p.) did not alter cocaine-induced increases in extracellular NAc DA levels. $* p<0.05$, $* * p<0.01$, **** $p<0.00$ I, compared to baseline (before cocaine) in each treatment group.

\section{DISCUSSION}

The major findings of this study are that activation of mGluR7 s by AMN082 dose-dependently inhibits the rewarding effects of cocaine, as assessed by electrical BSR and cocaine self-administration. In contrast, AMN082 had no effect on either locomotion or sucrose self-administration, suggesting a selective inhibition of cocaine reward. Intracranial microinjection of AMN082 into the NAc or VP, but not the dorsal striatum, dose-dependently inhibited cocaine self-administration. This effect was blocked by coadministration of MMPIP, a selective mGluR7 antagonist, suggesting an effect that is mediated by activation of mGluR7 $\mathrm{s}$ in the NAc-VP pathway. In vivo microdialysis showed that systemic administration of AMN082 altered neither basal nor cocaine-enhanced extracellular DA in the NAc or VP, but attenuated cocaine-induced inhibition of VP GABA release in both drug naive rats and cocaine selfadministration rats, suggesting that a NAc-VP GABAergic mechanism may underlie mGluR7 modulation of cocaine reward.

\section{mGluR7 Modulates Cocaine Reward}

Electrical BSR is a reliable and sensitive animal model for assessing the reward-relevant properties of addictive drugs (Stein and Ray, 1960; Wise and Gardner, 2004). Here, we found that cocaine significantly decreased BSR thresholds, indicative of summation between the reward induced by the electrical brain stimulation and that produced by cocaine. Strikingly, this cocaine-enhanced BSR was dose-dependently attenuated by AMN082 pretreatment. In contrast, AMN082 itself produced neither reward-like nor aversivelike effects on BSR, suggesting that mGluR7 is involved in cocaine's actions, but not in brain reward itself. This is significantly different from the effects produced by other mGluR compounds, such as the mGluR5 antagonist MPEP or the mGluR2/3 agonist LY379268, which themselves produce aversive-like BSR effects in addition to producing anticocaine or antinicotine effects (Kenny et al, 2005; Liechti and Markou, 2007). Thus, the present findings suggest that compounds targeting mGluR7 may have fewer unwanted side effects than other mGluR agents in the treatment of addiction.

Congruent with AMN082's antagonism of cocaineenhanced BSR, AMN082 dose-dependently inhibited cocaine self-administration under both FR2 and PR reinforcement. Given that low FR reinforcement schedules are thought to measure the fact of reinforcement, and PR reinforcement to measure the degree of reinforcing efficacy (O'Brien and Gardner, 2005; Arnold and Roberts, 1997), the present self-administration findings suggest involvement of mGluR7s in the rewarding effects of cocaine. As the same doses of AMN082 failed to alter oral sucrose self-administration, it is suggested that mGluR7s may selectively modulate cocaine's actions, rather than natural reward.

We note that AMN082 was recently reported to nonselectively inhibit locomotion, ethanol, and sucrose selfadministration in mice (Palucha et al, 2007; Salling et al, 2008). This raises the question of whether the present AMN082-induced attenuation of cocaine self-administration and cocaine-enhanced BSR was due to non-specific locomotor impairment. That appears unlikely, because, (1) AMN082 did not alter BSR $Y_{\max }$ levels, usually interpreted as measuring motoric capacity (Wise and Gardner, 2004); (2) the same doses of AMN082 did not alter high rates of operant responding for sucrose self-administration; (3) AMN082 altered neither basal nor cocaine-enhanced locomotion; and (4) intra-NAc or intra-VP perfusion of the same doses AMN082 that significantly inhibited cocaine self-administration did not inhibit rotarod performance, although a high systemic dose of AMN082 $(20 \mathrm{mg} / \mathrm{kg})$ did. These data suggest that AMN082, at high doses, may impair high rates of locomotor responding or motivated locomotion, but have no effect on low-rates of operant cocaine selfadministration behavior. These findings conflict with the observations of Salling et al (2008) in mice. The reasons for this discrepancy are unclear. They could relate to differences in species (rats $v s$ mice) and/or sucrose selfadministration protocols (drug naive rats $v s$ mice trained to self-administer sweetened ethanol).

Our previous studies have shown that AMN082 selectively alters extracellular GABA and glutamate, but not extracellular DA (Li et al, 2008), suggesting that AMN082's anticocaine 

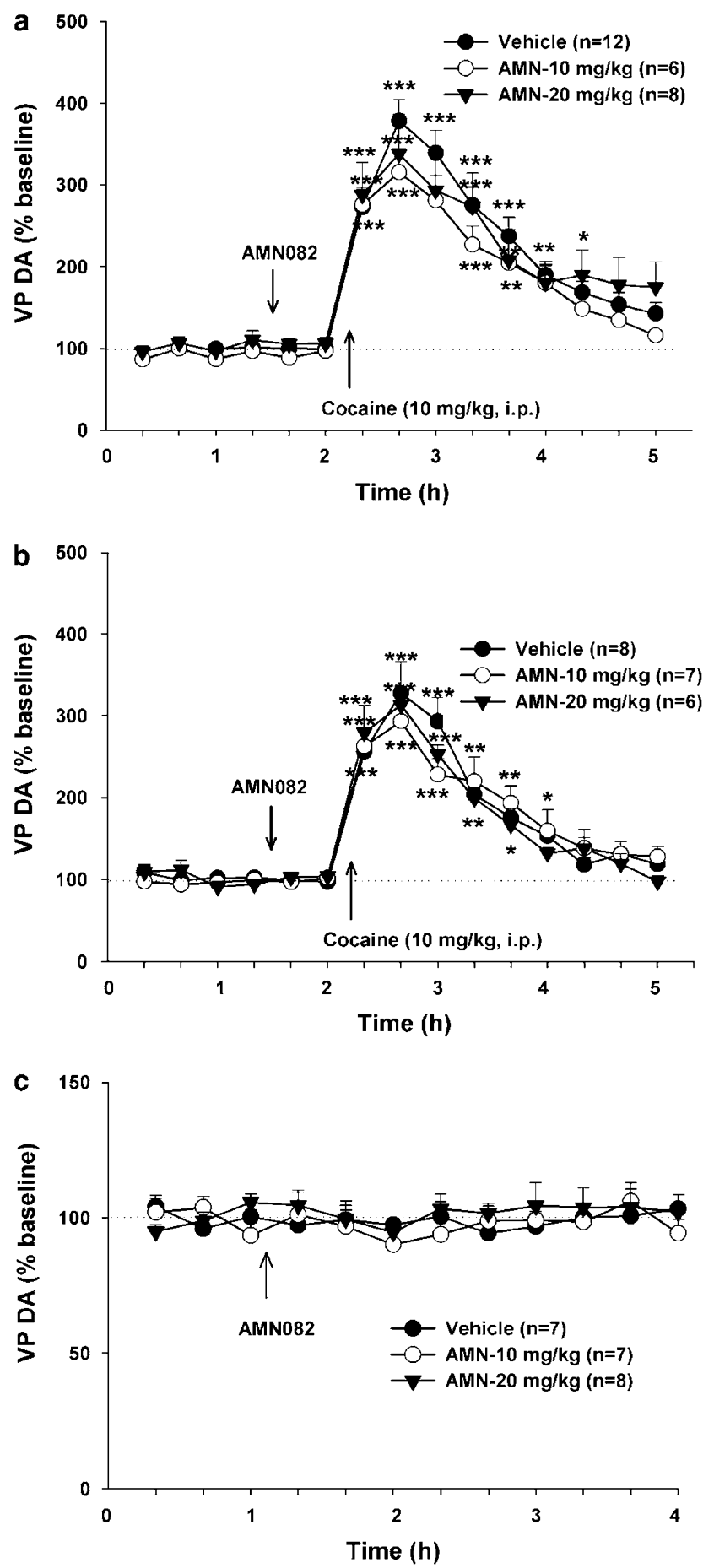

Figure 7 Effects of AMN082 on basal or cocaine-enhanced extracellular VP DA. (a and b) Illustrate that pretreatment with AMN082 (I0, $20 \mathrm{mg} / \mathrm{kg}$, i.p.) did not alter cocaine-induced increases in extracellular VP DA levels in either naive rats (a) or cocaine self-administration rats (b). (c) Illustrates that the same doses of AMN082 alone did not alter basal extracellular VP DA in drug naive rats. $* p<0.05$, $* * * 0.01$, $* * * * 0.001$, compared to baseline (before cocaine) in each treatment group.

effect may be mediated downstream of NAc DA transmission, that is, in the NAc-VP GABAergic pathway. To test this hypothesis, AMN082 was locally injected into the NAc, VP, and dorsal striatum where high densities of mGluR7 $\mathrm{s}$ are located (Bradley et al, 1998; Corti et al, 1998; Kinoshita et al,
Table I Mean Basal Levels of Extracellular VP, DA, and GABA in Drug-Naive Rats and Cocaine Self-Administration Rats

\begin{tabular}{lcc}
\hline \multicolumn{3}{c}{ Drug naive rats } \\
Group & DA (nM) & GABA (nM) \\
\hline Vehicle & $0.153 \pm 0.032(n=7)$ & $138.92 \pm 15.75(n=10)$ \\
AMN-10 mg/kg & $0.121 \pm 0.025(n=7)$ & $105.06 \pm 20.32(n=7)$ \\
AMN-20 mg/kg & $0.162 \pm 0.022(n=8)$ & $131.61 \pm 33.56(n=7)$ \\
& & \\
& Cocaine self-administration rats \\
Vehicle & $0.123 \pm 0.036(n=8)$ & $64.59 \pm 27.31(n=11) *$ \\
AMN-10 mg/kg & $0.103 \pm 0.039(n=7)$ & $72.84 \pm 21.94(n=8)$ \\
AMN-20 mg/kg & $0.124 \pm 0.059(n=6)$ & $84.60 \pm 30.01(n=7)$ \\
\hline
\end{tabular}

${ }^{*} p<0.05$, compared to the vehicle control group in naive rats.

1998). We found that microinjection of AMN082 into the NAc or VP, but not dorsal striatum, significantly inhibited cocaine self-administration in a dose-dependent manner, an effect that was blocked by intra-NAc or intra-VP coadministration of MMPIP, a selective mGluR7 allosteric antagonist (Suzuki et al, 2007). These data suggest that AMN082's anticocaine effect is mediated by activation of mGluR7s in a NAc-VP final common pathway mediating drug reward (Koob and Bloom, 1988; Xi and Gardner, 2008). The presynaptic and/or postsynaptic distribution of mGluR7s remains unclear. We have previously reported that activation of group III mGluRs or mGluR7s inhibits non-vesicular GABA and glutamate release in the NAc (Xi et al, 2003b; Li et al, 2008). Also, reduced NAc GABA after AMN082 administration may lead to an increase in vesicular glutamate release in the NAc through a $G_{A B A}$ receptor-mediated disinhibition mechanism (Li et al, 2008). Thus, mGluR7s may be located predominantly on extra-synaptic sites, modulating non-vesicular GABA and vesicular and/or non-vesicular glutamate release.

\section{Neurochemical Mechanisms Underlying mGluR7 Actions}

Mesocorticolimbic DA is widely regarded as playing a critical role in drug reward (Di Chiara and Bassareo, 2007). Yet, we found that AMN082 alters neither basal nor cocaineenhanced extracellular DA in the NAc or VP, suggesting that a non-DA-dependent mechanism underlies AMN082's actions. This finding appears to conflict with previous reports that the group III mGluR agonist L-AP4 inhibits DA release in the NAc and dorsal striatum (Hu et al, 1999; Mao et al, 2000). However, as L-AP4 has highest binding affinity for mGluR8, modest affinity for mGluR4, and lowest affinity for mGluR7 (Yang, 2005), we suggest that L-AP4's action on striatal DA release is likely mediated by activating non-mGluR7 group III receptor subtypes. This is consistent with the cellular distribution of mGluR7 receptorspredominantly on striatal glutamatergic and GABAergic terminals, rather than on DA terminals (Kosinski et al, 1999; Shigemoto et al, 1997).

Functional inhibition of postsynaptic NAc-VP GABAergic projection neurons has also been thought to play an 

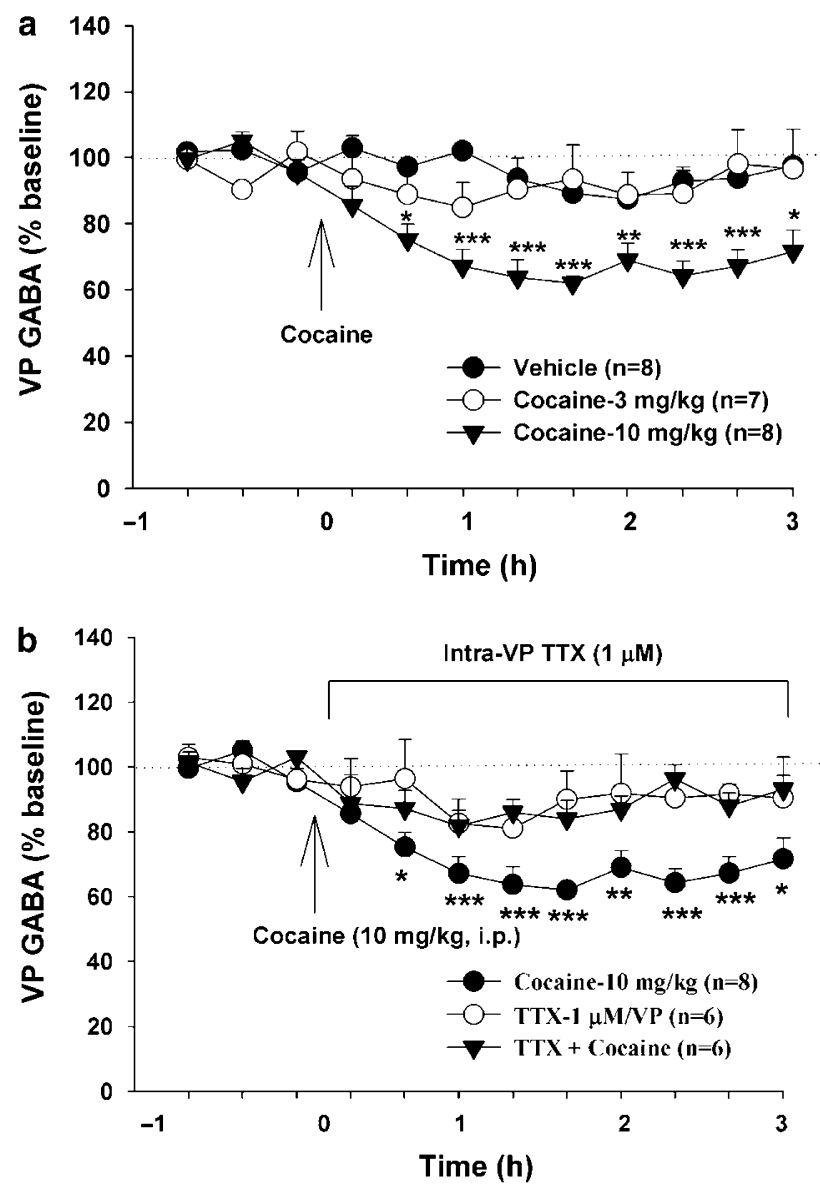

Figure 8 Effects of cocaine on extracellular VP GABA. (a) Illustrates the effect of cocaine on extracellular VP GABA. (b) Illustrates that cocaine's inhibitory effect on VP GABA was blocked by TTX. TTX alone did not significantly alter extracellular VP GABA levels. ${ }^{*} p<0.05$, $* * * 0.01$, **** $p<0.00$ I, compared to the pre-cocaine baseline.

important role in the rewarding effects of cocaine (Koob and Bloom, 1988; Wise, 1996; Xi and Gardner, 2008). Previous studies have shown that acute cocaine significantly lowers extracellular GABA levels in the VP (Tang et al, 2005; Torregrossa and Kalivas, 2008; Torregrossa et al, 2008). The mechanisms underlying cocaine-induced reduction of VP GABA release are not fully understood. Anatomically, the majority of neurons in the striatum are medium-spiny GABAergic output neurons, which project predominantly to the dorsal globus pallidus (from the dorsal striatum) or the VP (from the ventral striatum, ie, NAc) (Bennett and Bolam, 1994; Groenewegen et al, 1996). Given that acute cocaine elevates extracellular NAc DA, which, in general, produces a functional inhibitory effect on medium-spiny GABAergic neurons (predominantly by activation of $\mathrm{D}_{2}$-like DA receptors; Nicola and Malenka, 1997; Umemiya and Raymond, 1997; Centonze et al, 2002), we have previously suggested that a NAc DA mechanism may in part underlie cocaine-induced reduction in VP GABA release (Xi and Gardner, 2008). In addition, striatal GABAergic neurons also receive glutamatergic projections predominantly from the prefrontal cortex (Kalivas, 2004), which has been shown to be required for cocaine-induced reduction in VP GABA
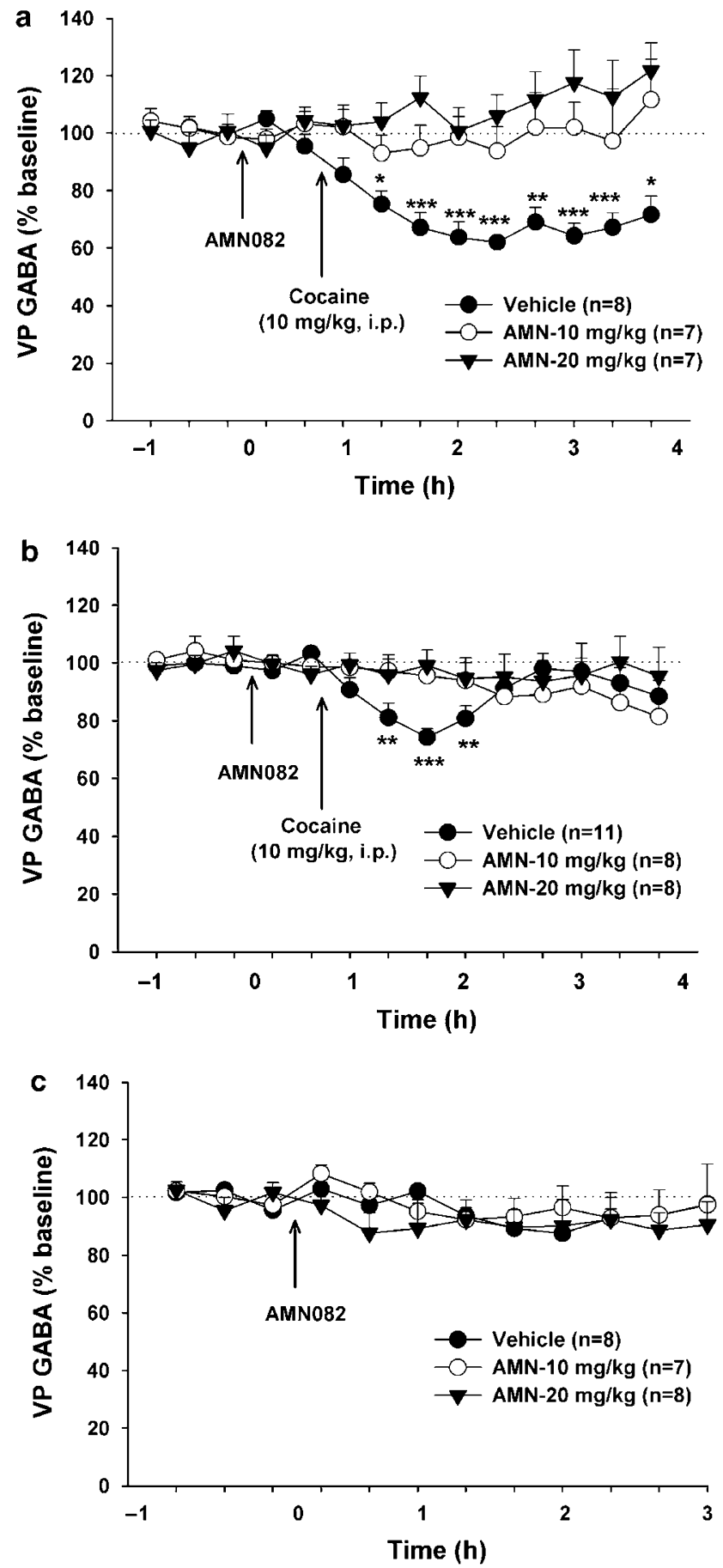

Figure 9 Effects of AMN082 on the cocaine-induced reduction in VP GABA release. ( $a$ and $b$ ) Illustrate that pretreatment with AMN082 (I0, $20 \mathrm{mg} / \mathrm{kg}$, i.p.) blocked cocaine's inhibitory effect on extracellular VP GABA in either naive rats (a) or cocaine self-administration rats (b). (c) Illustrates that the same doses of AMN082 alone failed to alter basal extracellular VP GABA levels. $* p<0.05, * * * 2<0.01$, **** $p<0.001$, compared to the precocaine baseline.

release (Torregrossa et al, 2008). Finally, local neuropeptides (such as neurotensin or enkephalin) co-released from VP GABAergic terminals and/or other afferents may also modulate cocaine's action on VP GABA release (Tang et al, 2005; Torregrossa and Kalivas, 2008). Thus, 

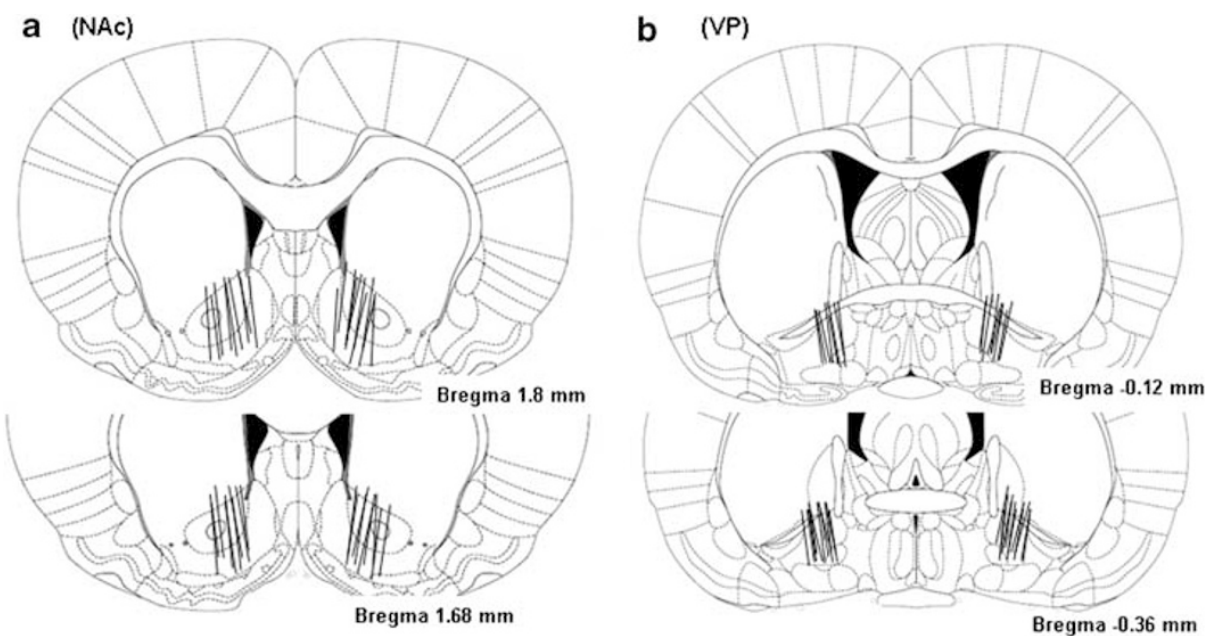

Figure 10 Schematic reconstructions of positions of microdialysis probes in rat brain, demonstrating that active microdialysis membranes tended to span the length of the core and shell compartments of the NAc (left panels), and of the VP (right panels).

cocaine-induced reduction in VP GABA release may well be a final net effect of multiple actions after cocaine administration. Whatever the exact mechanism, cocaine caused a dose-dependent reduction in VP GABA levels, an effect that was almost completely blocked by intra-VP administration of TTX, supporting a neuronal origin for cocaine-induced changes in VP GABA release, most likely from inhibition of NAc-VP GABAergic projection neurons. TTX alone did not significantly alter basal extracellular VP GABA levels, which is consistent with our previous finding in the NAc (Xi et al, 2003a, but see Bourdelais and Kalivas, 1992).

We should note that $2 \mathrm{mg} / \mathrm{kg}$ cocaine significantly enhanced BSR, whereas the same dose of cocaine had no effect (data not shown), $3 \mathrm{mg} / \mathrm{kg}$ only caused a detectable (not statistically significant) reduction, and $10 \mathrm{mg} / \mathrm{kg}$ cocaine was required to cause a significant reduction in extracellular VP GABA. The undetectable change in VP GABA after low doses of cocaine does not mean that cocaine had no effect on brain GABA release, because very low doses of cocaine significantly inhibit NAc GABAergic neuronal firing or synaptic GABAergic transmission during cocaine self-administration $(0.7 \mathrm{mg} / \mathrm{kg}$ i.v. $)$ or after local cocaine perfusion $(1 \mu \mathrm{M})$ as detected electrophysiologically (Centonze et al, 2002; Peoples et al, 2004). Thus, we interpret the undetectable change in VP GABA after low doses of cocaine as due to technical limitations of in vivo microdialysis (such as low neurotransmitter recovery rate and poor temporal resolution) and/or the result of cocaineinduced changes in neuronal GABA release that are insufficient to lead to a change in total extracellular GABA levels (see review by van der Zeyden et al, 2008).

Another important finding in the present study is that the cocaine-induced reduction in VP GABA release observed in cocaine self-administration rats appears to be smaller and shorter than that observed in drug naive rats. The underlying mechanisms are unclear. As basal levels of extracellular VP GABA levels are also lower in cocaine selfadministration rats than in drug-naive rats, we suggest that decreased basal levels of medium-spiny NAc GABAergic neuronal activity may in part contribute to reduced VP GABA response to acute cocaine. The decreased basal VP GABA levels could be related to a sustained increase in extracellular NAc DA during cocaine self-administration (Wise et al, 1995), and/or increased basal GABA levels in the NAc after repeated cocaine administration (Xi et al, 2003a). Both increased DA and GABA may inhibit NAc-VP GABAergic projection neurons. In addition, a recent study has shown that acute cocaine priming significantly increases extracellular NAc glutamate in cocaine self-administration rats, but not in drug naive rats (Miguéns et al, 2008), suggesting that increased NAc glutamate may also contribute to attenuated $\mathrm{VP}$ GABA response to cocaine by activation of medium-spiny GABAergic neurons.

Whatever the mechanisms underlying cocaine self administration-induced changes in VP GABA release, acute cocaine significantly lowered extracellular VP GABA levels in both drug naive and cocaine self-administration rats, suggesting an important role for NAc-VP GABAergic mechanisms in mediating cocaine reward. Strikingly, pretreatment with AMN082 significantly attenuated cocaine's inhibitory effect on VP GABA release, suggesting mGluR7 involvement in cocaine's action on VP GABA. We have previously reported that systemic administration of AMN082 inhibits GABA, while increasing glutamate release in the NAc (Li et al, 2008). We suggest that these changes may enhance excitability of postsynaptic medium-spiny GABAergic projection neurons, thereby antagonizing cocaine-induced inhibition of VP GABA release. We have noted that systemic administration of AMN082 failed to alter VP DA or GABA release, whereas intra-VP microinjections of AMN082 inhibited cocaine selfadministration. Further studies are needed to determine whether microinjections of AMN082 into the NAc or VP block cocaine-induced changes in VP DA or GABA.

In conclusion, this study demonstrates that the group III mGluR7 receptor subtype plays an important role in the rewarding effects of cocaine. The ventral striatopallidal GABAergic pathway appears to play an important role in AMN082's action on cocaine reward. These findings suggest 
further exploration of AMN082 or other mGluR7 agonists as potentially useful treatments for cocaine addiction.

\section{ACKNOWLEDGEMENTS}

This research was supported by the Intramural Research Program of the National Institute on Drug Abuse, National Institutes of Health, Department of Health and Human Services.

\section{DISCLOSURE/CONFLICT OF INTEREST}

All authors hereby declare that, except for income received from their respective primary employers, no financial support or compensation has been received from any individual or corporate entity over the past three years for research or professional services. There are no personal financial holdings that could be perceived as constituting a potential conflict of interest.

\section{REFERENCES}

Arnold JM, Roberts DCS (1997). A critique of fixed and progressive-ratio schedules used to examine the neural substrates of drug reinforcement. Pharmacol Biochem Behav 57: 441-447.

Bennett BD, Bolam JP (1994). Synaptic input and output of parvalbumin-immunoreactive neurons in the neostriatum of the rat. Neuroscience 62: 707-719.

Bourdelais AJ, Kalivas PW (1992). Modulation of extracellular gamma-aminobutyric acid in the ventral pallidum using in vivo microdialysis. J Neurochem 58: 2311-2320.

Bradley SR, Rees HD, Yi H, Levey AI, Conn PJ (1998). Distribution and developmental regulation of metabotropic glutamate receptor 7a in rat brain. J. Neurochem 71: 636-645.

Callaerts-Vegh Z, Beckers T, Ball SM, Baeyens F, Callaerts PF, Cryan JF et al (2006). Concomitant deficits in working memory and fear extinction are functionally dissociated from reduced anxiety in metabotropic glutamate receptor 7-deficient mice. J Neurosci 26: 6573-6582.

Centonze D, Picconi B, Baunez C, Borrelli E, Pisani A, Bernardi G et al (2002). Cocaine and amphetamine depress striatal GABAergic synaptic transmission through D2 dopamine receptors. Neuropsychopharmacology 26: 164-175.

Corti C, Restituito S, Rimland JM, Brabet I, Corsi M, Pin JP et al (1998). Cloning and characterization of alternative mRNA forms for the rat metabotropic glutamate receptors mGluR7 and mGluR8. Eur J Neurosci 10: 3629-3641.

Cryan JF, Kelly PH, Neijt HC, Sansig G, Flor PJ, van Der Putten H (2003). Antidepressant and anxiolytic-like effects in mice lacking the group III metabotropic glutamate receptor mGluR7. Eur J Neurosci 17: 2409-2417.

David HN, Abraini JH (2003). Blockade of the locomotor stimulant effects of amphetamine by group I, group II, and group III metabotropic glutamate receptor ligands in the rat nucleus accumbens: possible interactions with dopamine receptors. Neuropharmacology 44: 717-727.

Di Chiara G, Bassareo V (2007). Reward system and addiction: what dopamine does and doesn't do. Curr Opin Pharmacol 7: 69-76.

Fendt M, Schmid S, Thakker DR, Jacobson LH, Yamamoto R, Mitsukawa $\mathrm{K}$ et al (2007). mGluR7 facilitates extinction of aversive memories and controls amygdala plasticity. Mol Psychiatry 13: 970-979.
Ferraguti F, Shigemoto R (2006). Metabotropic glutamate receptors. Cell Tissue Res 326: 483-504.

Groenewegen HJ, Wright CI, Beijer AV (1996). The nucleus accumbens: gateway for limbic structures to reach the motor system? Prog Brain Res 107: 485-511.

Hu G, Duffy P, Swanson C, Ghasemzadeh MB, Kalivas PW (1999). The regulation of dopamine transmission by metabotropic glutamate receptors. J Pharmacol Exp Ther 289: 412-416.

Kalivas PW (2004). Glutamate systems in cocaine addiction. Curr Opin Pharmacol 4: 23-29.

Kenny PJ, Boutrel B, Gasparini F, Koob GF, Markou A (2005). Metabotropic glutamate 5 receptor blockade may attenuate cocaine self-administration by decreasing brain reward function in rats. Psychopharmacology 179: 247-254.

Kenny PJ, Markou A (2004). The ups and downs of addiction: role of metabotropic glutamate receptors. Trends Pharmacol Sci 25: 265-272.

Kinoshita A, Shigemoto R, Ohishi H, van der Putten H, Mizuno N (1998). Immunohistochemical localization of metabotropic glutamate receptors, mGluR7a and mGluR7b, in the central nervous system of the adult rat and mouse: a light and electron microscopic study. J Comp Neurol 393: 332-352.

Koob GF, Bloom FE (1988). Cellular and molecular mechanisms of drug dependence. Science 242: 715-723.

Kosinski CM, Bradley SR, Conn PJ, Levey AI, Landwehrmeyer GB, Penney Jr JB et al (1999). Localization of metabotropic glutamate receptor $7 \mathrm{mRNA}$ and mGluR7a protein in the rat basal ganglia. J Comp Neurol 415: 266-284.

Li X, Gardner EL, Xi Z-X (2008). The metabotropic glutamate receptor $7\left(\mathrm{mGluR}_{7}\right)$ allosteric agonist AMN082 modulates nucleus accumbens GABA and glutamate, but not dopamine, in rats. Neuropharmacology 54: 542-551.

Liechti ME, Markou A (2007). Metabotropic glutamate 2/3 receptor activation induced reward deficits but did not aggravate brain reward deficits associated with spontaneous nicotine withdrawal in rats. Biochem Pharmacol 74: 1299-1307.

Mao L, Lau Y-S, Wang JQ (2000). Activation of group III metabotropic glutamate receptors inhibits basal and amphetamine-stimulated dopamine release in rat dorsal striatum: an in vivo microdialysis study. Eur J Pharmacol 404: 289-297.

Mao L, Wang JQ (2000). Distinct inhibition of acute cocainestimulated motor activity following microinjection of a group III metabotropic glutamate receptor agonist into the dorsal striatum of rats. Pharmacol Biochem Behav 67: 93-101.

Marino MJ, Conn JP (2002). Modulation of the basal ganglia by metabotropic glutamate receptors: potential for novel therapeutics. Curr Drug Targets CNS Neurol Disord 1: 239-250.

Miguéns M, Del Olmo N, Higuera-Matas A, Torres I, GarcíaLecumberri C, Ambrosio E (2008). Glutamate and aspartate levels in the nucleus accumbens during cocaine self-administration and extinction: a time course microdialysis study. Psychopharmacology 196: 303-313.

Mitsukawa K, Yamamoto R, Ofner S, Nozulak J, Pescott O, Lukic S et al (2005). A selective metabotropic glutamate receptor 7 agonist: activation of receptor signaling via an allosteric site modulates stress parameters in vivo. Proc Natl Acad Sci USA 102: 18712-18717.

Nicola SM, Malenka RC (1997). Dopamine depresses excitatory and inhibitory synaptic transmission by distinct mechanisms in the nucleus accumbens. J Neurosci 17: 5697-5710.

O'Brien CP, Gardner EL (2005). Critical assessment of how to study addiction and its treatment: human and non-human animal models. Pharmacol Ther 108: 18-58.

Palucha A, Klak K, Branski P, van der Putten H, Flor PJ, Pilc A (2007). Activation of the mGlu7 receptor elicits antidepressantlike effects in mice. Psychopharmacology 194: 555-562.

Paxinos G, Watson C (1998). The Rat Brain in Stereotaxic Coordinates 4th edn. Academic Press: New York. 
Peoples LL, Lynch KG, Lesnock J, Gangadhar N (2004). Accumbal neural responses during the initiation and maintenance of intravenous cocaine self-administration. J Neurophysiol 91: 314-323.

Richardson NR, Roberts DCS (1996). Progressive ratio schedules in drug self-administration studies in rats: a method to evaluate reinforcing efficacy. J Neurosci Methods 66: 1-11.

Salling MC, Faccidomo S, Hodge CW (2008). Nonselective suppression of operant ethanol and sucrose self-administration by the mGluR7 positive allosteric modulator AMN082. Pharmacol Biochem Behav 91: 14-20.

Sansig G, Bushell TJ, Clarke VR, Rozov A, Burnashev N, Portet C et al (2001). Increased seizure susceptibility in mice lacking metabotropic glutamate receptor 7. J Neurosci 21: 8734-8745.

Shigemoto R, Kinoshita A, Wada E, Nomura S, Ohishi H, Takada $M$ et al (1997). Differential presynaptic localization of metabotropic glutamate receptor subtypes in the rat hippocampus. J Neurosci 17: 7503-7522.

Stein L, Ray OS (1960). Brain stimulation reward "thresholds" self-determined in rat. Psychopharmacologia 1: 251-256.

Suzuki G, Tsukamoto N, Fushiki H, Kawagishi A, Nakamura M, Kurihara $\mathrm{H}$ et al (2007). In vitro pharmacological characterization of novel isoxazolopyridone derivatives as allosteric metabotropic glutamate receptor 7 antagonists. J Pharmacol Exp Ther 323: 147-156.

Tang X-C, McFarland K, Cagle S, Kalivas PW (2005). Cocaineinduced reinstatement requires endogenous stimulation of $\mu$-opioid receptors in the ventral pallidum. J Neurosci 25: 4512-4520.

Torregrossa MM, Kalivas PW (2008). Neurotensin in the ventral pallidum increases extracellular gamma-aminobutyric acid and differentially affects cue- and cocaine-primed reinstatement. J Pharmacol Exp Ther 325: 556-566.

Torregrossa MM, Tang X-C, Kalivas PW (2008). The glutamatergic projection from the prefrontal cortex to the nucleus accumbens core is required for cocaine-induced decreases in ventral pallidal GABA. Neurosci Lett 438: 142-145.

Umemiya M, Raymond LA (1997). Dopaminergic modulation of excitatory postsynaptic currents in rat neostriatal neurons. J Neurophysiol 78: 1248-1255. van der Zeyden M, Oldenziel WH, Rea K, Cremers TI, Westerink $\mathrm{BH}$ (2008). Microdialysis of GABA and glutamate: analysis, interpretation and comparison with microsensors. Pharmacol Biochem Behav 90: 135-147.

Wise RA (1996). Addictive drugs and brain stimulation reward. Annu Rev Neurosci 19: 319-340.

Wise RA, Gardner EL (2004). Animal models of addiction. In: Charney DS, Nestler EJ (eds). Neurobiology of Mental Illness 2nd edn. Oxford Univ Press: London. pp 683-697.

Wise RA, Newton P, Leeb K, Burnette B, Pocock D, Justice Jr JB (1995). Fluctuations in nucleus accumbens dopamine concentration during intravenous cocaine self-administration in rats. Psychopharmacology 120: 10-20.

Wolf NI, Willemsen MAAP, Engelke UF, van der Knaap MS, Pouwels PJW, Harting I et al (2004). Severe hypomyelination associated with increased levels of $\mathrm{N}$-acetylaspartylglutamate in CSF. Neurology 62: 1503-1508.

Xi Z-X, Gardner EL (2008). Hypotheses-driven medication discovery for the treatment of psychostimulant addiction. Curr Drug Abuse Rev 1: 303-327.

Xi Z-X, Gilbert JG, Peng X-Q, Pak AC, Li X, Gardner EL (2006a). Cannabinoid $\mathrm{CB}_{1}$ receptor antagonist AM251 inhibits cocaineprimed relapse in rats: role of glutamate in the nucleus accumbens. J Neurosci 26: 8531-8536.

Xi Z-X, Newman AH, Gilbert JG, Pak AC, Peng X-Q, Ashby Jr CR et al (2006b). The novel dopamine $\mathrm{D}_{3}$ receptor antagonist NGB 2904 inhibits cocaine's rewarding effects and cocaine-induced reinstatement of drug-seeking behavior in rats. Neuropsychopharmacology 31: 1393-1405.

Xi Z-X, Ramamoorthy S, Shen H, Lake R, Samuvel DJ, Kalivas PW (2003a). GABA transmission in the nucleus accumbens is altered after withdrawal from repeated cocaine. I Neurosci 23: 3498-3505.

Xi Z-X, Shen H, Baker DA, Kalivas PW (2003b). Inhibition of nonvesicular glutamate release by group III metabotropic glutamate receptors in the nucleus accumbens. J Neurochem 87: 1204-1212.

Yang Z-Q (2005). Agonists and antagonists for group III metabotropic glutamate receptors 6,7 and 8. Curr Top Med Chem 5: 913-918. 